\title{
Competing for Endorsements
}

\section{Citation}

Grossman, Gene M, and Elhanan Helpman. 1999. "Competing for Endorsements." American Economic Review 89 (3): 501-24. https://doi.org/10.1257/aer.89.3.501.

\section{Permanent link}

http://nrs.harvard.edu/urn-3:HUL.InstRepos:37978935

\section{Terms of Use}

This article was downloaded from Harvard University's DASH repository, and is made available under the terms and conditions applicable to Other Posted Material, as set forth at http:// nrs.harvard.edu/urn-3:HUL.InstRepos:dash.current.terms-of-use\#LAA

\section{Share Your Story}

The Harvard community has made this article openly available.

Please share how this access benefits you. Submit a story.

Accessibility 


\title{
COMPETING FOR ENDORSEMENTS *
}

\author{
by
}

Gene M. Grossman ${ }^{1}$ and Elhanan Helpman ${ }^{2}$

Working Paper No.9-98

May, 1998

\footnotetext{
Princeton University.

2 The Eitan Berglas School of Economics, Tel-Aviv University, Harvard University and CIAR.

* We thank David Austen-Smith, Elchanan Ben-Porath, Avinash Dixit, Dennis Epple, Jacob Glazer, Faruk Gul, Eliana Laferra, Giovanni Maggi, Adi Pauzner, Ariel Rubinstein and two annonymous referees for helpful discussions and comments, and the National Science Foundation and the U.S.-Israel Binational Science Foundation for financial support.
} 


\section{Introduction}

In most elections the leaders of organized interest groups publicly announce their support for one candidate or slate of candidates or another. Why are these political endorsements made? And what role do they play in the election process and in the determination of policy?

We see public endorsements as a means of communication between the well informed leaders of special interest groups and the lesser informed rank-and-file members. The members of an interest group may not fully understand how a particular policy outcome will affect their well being or where the various candidates stand on the issues. Moreover, it may be costly for these individuals to acquire all of the information they need to vote "correctly". Indeed, the cost of gathering information can easily exceed the private gains they might expect to achieve with their single votes. Then the individuals may look for readily available cues to guide them in the polling booth. In this context, endorsements by group leaders may convey useful information to like-minded voters, and perhaps to others.

If groups of voters use endorsements as cues, then candidates and parties may well have incentives to compete for these endorsements. Such competition would have the candidates announcing platforms that appeal to the leaders of the various groups. ${ }^{1}$ Thus, the endorsement process might give special interests a means to extract policy concessions that come at the expense of the general public. One of the goals of this paper is to examine the conditions under which the ability to make endorsements bestows political power to the members of special interest groups and the extent to which policy outcomes are skewed as a result.

In conducting an analysis of endorsements, it is important to recognize that.announcements of support are a coarse language for communication. An endorsement provides only a binary comparison between candidates in a situation where voters might need a more detailed report in order to cast their votes optimally. The

\footnotetext{
${ }^{1}$ For example, Rapaport et al. (1991) describe the bidding for support from labor, women's and teachers' groups by candidates for the Democratic presidential nomination in 1984. They conclude that the "groups received tangible rewards in the form of platform commitments."
} 
coarse nature of the endorsement may explain why it can be communicated relatively cheaply; the identity of the backed individual or party can be relayed in a simple message requiring little input from the recipient to be "heard". But the members of an interest group may share only certain policy preferences with their associates, while holding personal views on a host of other issues. For example, the members of a labor union may be united in their feelings about the minimum wage and trade liberalization, but differ in their opinions about abortion and gun control. Then it would not be enough for the union members to know that their leaders preferred one candidate or party to another; they would also wish to know the intensity of those preferences. Only then could these voters weigh their concerns over labor matters against their interests in other policy dimensions. In short, the coarseness of the endorsement message space confronts the recipients with a signal-extraction problem. Our paper employs concepts used in analyzing games of asymmetric information to shed light on this problem.

In this paper we develop a simple model of a two-party election with interestgroup endorsements. We consider an election to determine the composition of a legislative body, which in turn will be called upon to set two policies. On one of the issues the parties have fixed and invariant positions, reflecting perhaps their different ideologies. On the other issue the positions of the parties are assumed pliable. The parties announce their platforms on this issue with an eye toward maximizing their shares of the vote. On both the fixed (ideological) and pliable issues, the policy outcome is taken to be a compromise between the positions of the parties, with weights that reflect the composition of the legislature.

All voters know the positions of the parties on the ideological issue and their own preferences regarding this issue. They also know the stated positions on the pliable policy issue. However, they do not fully comprehend how the various levels of this policy instrument would affect them personally. For example, voters might know that one party favors a minimum wage of $\$ 4.25$ per hour while the other favors a wage of $\$ 5$ per hour, yet they may be unsure about how the minimum wage impinges on their own expected income. We model this imperfect information as uncertainty in 
the minds of voters as to their own ideal point in the (pliable) policy space.

Certain of the voters are members of organized interest groups. Each such group comprises voters who share similar interests with respect to the pliable policy issue. When the members learn the positions of the two parties and hear which has been endorsed by their leader, they gain information about where their interests might lie. This new information allows these voters to update their beliefs about their expected ideal point. Using their updated beliefs, the group members assess the pliable platforms of the two parties, and weigh the differences against their own personal feelings about the parties' ideological stances.

The timing of the model is as follows. First, the parties announce positions on the pliable issue. Then the leaders issue their endorsements. We consider both the case where the leaders follow mechanical rules in assigning their support and where they behave strategically in doing so. After hearing the endorsements, the voters head to the polls. Each voter casts her ballot so as to maximize her expected utility in view of the beliefs she holds at the time of the election. Finally, the election determines the composition of the legislature, which in turn determines the policy outcomes.

The remainder of the paper is organized as follows. In the next section we describe the few previous papers that have focused on political endorsements and indicate the place of our work in this literature. Section 3 gives the details of our model and examines the benchmark case of no endorsements (or, equivalently, endorsements that are totally uninformative). In Section 4 , we derive a neutrality result. Suppose there is only one interest group and the members of this group have interests that are perfectly complementary to the rest of the voting population. Then, if the group leader's endorsement is heard by all voters and they all draw similar inferences from it, the policy positions and election outcome are the same as in the benchmark case. This result suggests conditions under which endorsements may have electoral impacts: when they are not (perfectly) observed by non-members of the interest group or when the interests of group members are not (perfectly) complementary to those of the outsiders. In Section 5, we describe an equilibrium that can arise under either of these circumstances, assuming the existence of a single interest group whose leader 
follows a simple endorsement rule. This equilibrium is further examined in Section 6 , where we evaluate its efficiency properties and compare the group members' welfare to what would obtain were they perfectly informed. Section 7 extends the model to the case where the leader of the interest group behaves strategically. Then, in Section 8 , we reintroduce the assumption of mechanical endorsements while allowing for multiple interest groups. Section 9 concludes.

\section{The Literature on Political Endorsements}

Much of the literature on the role of interest groups in electoral competition and policy determination has focused on campaign contributions. Baron (1994), for example, studied an election in which interest groups contribute resources to the parties whose positions they prefer, and parties use these tributes to fund spending aimed at impressionable voters. Our own previous work (1994 and 1996a) has examined how contributors might use their giving to influence directly the positions adopted by policy makers and political parties.

While there is no denying the importance of campaign contributions in American politics and elsewhere, the literature's thorough investigation of them has perhaps diverted analytical attention from other tools that groups can and do use in their efforts to influence political outcomes. Political endorsements, for example, although prominent in many elections, have received scant attention in the literature.

McKelvey and Ordeshook (1985) were the first to identify group endorsements as a potential source of information for imperfectly informed voters. In their model, a subset of voters does not know the positions of two candidates in a policy space represented by the real line. These voters acquire information by observing the outcomes of a sequence of "polls" taken prior to the election. Endorsements are assumed to provide additional information; they allow voters to identify the candidate whose position is further to the left or the right.

The endorsement process is left implicit in the paper by McKelvey and Ordeshook, but is treated explicitly by Grofman and Norrander (1990). In their model, two 
candidates have fixed positions on the real line. These positions are obscure to the single voter. The voter takes his cues from two knowledgeable "endorsers" whose preferences are known to him. Each endorser is assumed to support her favorite candidate, either invariably, or in the event that the candidate's position lies within some maximum distance from her own ideal point. The voter updates his beliefs based on his observation of these (non-strategic) endorsements.

Lupia (1992) and Cameron and Jung (1995) consider the role of endorsements in referendum voting. In each case there is a status quo point on the real line and an "agenda setter" who can propose an alternative. The setter has preferences over policy outcomes and designs a proposal to maximize her welfare, knowing that the initiative will displace the status quo only if it garners majority support. The voters do not observe the proposal directly (e.g., they do not understand the details of the referendum initiative), but they do know the utility function of its proponent. Lupia introduces a non-strategic endorser who informs voters whether the proposal is to the left or the right of the status quo. In contrast, Cameron and Jung allow the endorser to behave strategically. Their endorser, who has preferences like anyone else, chooses whether to support the proposal or not in order to further her own self interest. The voters know the endorser's preferences and use the information implicit in her decision to update their beliefs.

Several features distinguish our paper from these earlier ones. First, we allow two political parties to compete for endorsements. That is, the parties consider how their positions will affect the endorsers' pronouncements and factor this in when choosing their platforms. Of course, this is not possible in Grofman and Norrander's model, where the candidates' positions are fixed exogenously. The agenda setter studied by Lupia and by Cameron and Jung does anticipate the actions of the endorser(s), but the status quo policy is taken as given in their setting. Second, we consider an election with multiple policy dimensions, only some of which are of concern to the endorsers. This is important, as we noted in the introduction, because it forces the voters to assess the likely quantitative significance of the endorsement, and not just its qualitative significance. Our paper treats both the case of an endorser who 
follows a mechanical rule, as in Grofman and Norrander (1990) and Lupia (1992), and one who is a strategic agent, as in Cameron and Jung (1995). In short, ours is the first paper,so far as we know, that seeks to reconcile the simultaneous and complex interactions between multiple office-seeking politicians, self-interested endorsers, and welfare-maximizing voters.

Our paper follows the previous literature by isolating endorsements from the other actions that interest groups might undertake to influence political outcomes. In particular, our model allows no role for campaign contributions. While it is true that contributions and endorsements often come hand in hand, these tools seem aimed at different audiences. The intent of contributors may be to purchase influence directly or to signal to politicians a group's keen concern about a particular issue (see Ball, 1995). Indeed, groups often attempt to conceal their contributions from the public to the extent possible. Endorsements, on the other hand, are public announcements explicitly intended to convey information to voters. In any event, it seems a natural first step to try to understand the role of endorsements in isolation, before addressing their effectiveness in more complicated settings where several tools are being used at once. Ultimately, of course, we would like to understand what instruments different groups will use in different political environments, and how the various tools interact.

\section{The Model and a Benchmark}

We study the competition between two political parties for seats in a legislature. The legislature will be called upon to set two policies. On one issue the positions of the two parties are assumed to be fixed. These positions might reflect, for example, the parties' political ideologies or their stated goals on an issue of long-standing deliberation. It may be difficult for the parties to change such committed positions in the course of a single campaign. In contrast, the parties' positions on the second issue are perfectly pliable. The politicians have no particular preferences concerning the outcome in this dimension and view their platforms as tactical choices in the electoral competition. Our analysis focuses on the determination of the pliable policy. 
The election will determine the composition of the legislature via proportional representation. After the election, the legislature will meet to set the levels of the two policies. The outcome of this will depend inter alia on the rules and institutions of the governing body and the nature of the negotiating process. Rather than modeling these in any detail, we simply assume that the legislature achieves a compromise agreement giving more weight to a party's platform the greater the size of its delegation. In particular, let $q^{A}$ and $q^{B}$ denote the positions of the parties on the fixed policy issue, and normalize these positions so that $q^{A}=0$ and $q^{B}=1$. Let $p^{A}$ and $p^{B}$ be their positions on the pliable issue, where $p^{j}$ is any real number between 0 and 1 . We assume

$$
p=\psi(s) p^{A}+[1-\psi(s)] p^{B}
$$

and

$$
q=1-\psi(s)
$$

where $p$ and $q$ are the policy outcomes in the pliable and fixed dimension, $s$ is the fraction of seats captured by party $A$, and $\psi(s)$ is the weight attached to this party's position in forming the policy compromise. We also assume that $\psi^{\prime}(s) \geq 0$ for all $s$ and that $\psi(s)=1-\psi(1-s)$; the latter means that the parties have equal ability to bargain over policies given the number of seats they control.

The objective of each party is to maximize its presence in the legislature. This objective might reflect a party's desire for a fixed policy outcome close to its ideological ideal, or the parties might seek to maximize the patronage they can distribute while believing that the spoils of office expand with the size of the delegation. In any event, the parties' pronouncements on the pliable policy are their sole tools of electoral competition.

Voters are numerous and distinguished by their preferences over the two policy outcomes. For any policy vector $(p, q)$ the utility of a voter with taste parameters $(\pi, \beta)$ is given by

$$
u(p, q)=-a(p-\pi)^{2}+\beta q .
$$

Here, $\pi \in[0,1]$ identifies the voter's ideal point in the pliable policy space and $\beta$ indicates her relative preference (positive or negative) for the fixed policy position of 
party $B$.

We assume that all voters know their tastes for the fixed policy and know how to evaluate the possible policy outcomes. This issue might be ideologically charged or one of long-standing contention - as we have already noted - and so voters may have discussed it thoroughly or witnessed many reports on it in the media. Voters are less well informed about the pliable issue. In particular, because this is a new or complicated issue, voters do not recognize the relationship between the level of the policy instrument and their own well being. We model a voter's imperfect understanding of the policy issue as uncertainty about the location of her ideal point $\pi$.

Voters fall into one of two categories. A fraction $n$ of the voters belong to a special interest group. (For now, we assume there is only one such group; but see Section 8 for an extension to the many-group case.) These voters, whom we refer to as insiders, know that they share similar goals for the pliable policy. In particular, an insider is aware that her group comprises a set of voters whose ideal pliable policy is $\pi_{I}{ }^{2}$ The typical insider holds the prior belief that her group's ideal point has been drawn from some distribution with support $[0,1]$; we denote by $F\left(\pi_{I}\right)$ the cumulative distribution function associated with these beliefs and assume that it is log-concave (i.e., that $\log F\left(\pi_{I}\right)$ is a concave function of $\left.\pi_{I}\right)$. This is a relatively weak restriction satisfied by the uniform and triangular distributions, and many others. Also, we assume that the density $f\left(\pi_{I}\right) \equiv F^{\prime}\left(\pi_{I}\right)$ is strictly positive and symmetric about $\frac{1}{2}$. We record these restrictions in the following

Assumption 1 The cumulative distribution function $F\left(\pi_{I}\right)$ of prior beliefs about $\pi_{I}$ is $\log$-concave for all $\pi_{I} \in[0,1]$, and its density function $f\left(\pi_{I}\right)$ is positive and symmetric around $\frac{1}{2}$.

Although the interest-group members hold identical preferences with respect to the pliable policy issue, this does not mean that they all feel similarly about the two political parties. We suppose, in fact, that insiders hold disparate views on

\footnotetext{
${ }^{2}$ In our working paper (1996b), we supposed that insiders' interests regarding the pliable issue are not identical, but rather the group comprises a set of voters whose ideal pliable policy is uniformly distributed over some range. This alternative specification gives nearly identical results.
} 
the fixed policy issue, much like the voting population at large. For each possible value of $\pi$ for an insider, the conditional distribution of $\beta$ is uniform on the interval $\left[-\frac{1}{2 k}-\frac{b}{k}, \frac{1}{2 k}-\frac{b}{k}\right], k>0$ and $|b|<\frac{1}{2}$. Here $k$ is the density of the conditional distribution and so $\frac{1}{k}$ measures the diversity of opinions. The parameter $b$ indicates the average preference among insiders for the fixed position of party $A$.

The remaining fraction $1-n$ of voters do not belong to any interest group. Later, we will distinguish situations where these outsiders believe that there is a relationship between their own interests in the pliable policy and that of the insiders from cases where they believe no such relationship exists. For now, we only assume that an outsider holds the prior belief that her ideal point has been drawn from some symmetric distribution with mean $\frac{1}{2}$ and support $[0,1]$. Among these voters, too, the distribution of $\beta$ conditional on $\pi$ is uniform on $\left[-\frac{1}{2 k}-\frac{b}{k}, \frac{1}{2 k}-\frac{b}{k}\right]$.

Each voter recognizes that the policy outcome will be a compromise between the positions of the two parties. A ballot cast for party $A$ will augment slightly the seat count of that party, and so increase the weight attached to its platform in forming the compromise. An individual votes for party $A$ if and only if, given her beliefs at the time of the election, she perceives that the implied change in policy outcome would raise her expected utility. More formally, let $\Omega$ denote the information available to a voter at the time of the election and let $\mathcal{E}$ represent the expectation operator. Then the voter casts her ballot for party $A$ if and only if $d \mathcal{E}[u(p, q \mid \Omega)] / d s \geq 0$. Using (1), $(2)$, and (3), we can restate the voting rule $\mathrm{s}^{3}$

$$
\text { vote for party } A \text { iff } \beta \leq 2 a(p-\mathcal{E}[\pi \mid \Omega])\left(p^{B}-p^{A}\right) \text {. }
$$

The voter compares the anticipated compromise on the pliable issue to her expected ideal point, basing the expectation on her beliefs at the time of the election. If the former is larger (smaller), then she votes for the party with the lower (higher) position on the pliable issue, unless her relative preference for the other party's fixed policy

\footnotetext{
${ }^{3}$ Since very few voters will be indifferent between voting for party $A$ and voting for party $B$, it does not matter whether we assume that all of these voters vote for $A$ or that each such voter selects randomly.
} 
position is great. This specification presumes that each voter correctly forecasts the compromise outcomes for $p$ and $q$; i.e., that voters have rational expectations.

We allow for the possibility that insiders and outsiders have access to different information sets; e.g., insiders will have observed the endorsement issued by their group's leader while outsiders may not have done so. Then, to calculate the fraction of votes captured by each party, we need to compute separately the fractions among each voter category and take a weighted average of the two. Using (4) and the assumed distribution of $\beta$, we find that party $A$ captures a fraction

$$
s=\frac{1}{2}+b+2 k a\left(p-n \mathcal{E}_{I}\left[\pi \mid \Omega_{I}\right]-(1-n) \mathcal{E}_{O}\left[\pi \mid \Omega_{O}\right]\right)\left(p^{B}-p^{A}\right)
$$

of the votes, where $\mathcal{E}_{I}(\cdot)$ and $\mathcal{E}_{O}(\cdot)$ are the expected values of $\pi$ among insiders and outsiders, respectively, and $\Omega_{I}$ and $\Omega_{O}$ are the information sets available to these two types of voters. ${ }^{4}$ This is also party $A$ 's share of the legislative seats.

We seek to characterize a Perfect Bayesian Equilibrium (PBE) of a game with the following sequence of stages. First, nature chooses $\pi_{I}$ from the distribution $F\left(\pi_{I}\right)$ on $[0,1]$. This "choice" is revealed to the political parties and the leader of the interest group, but not to the individual voters. ${ }^{5}$ Second, the parties simultaneously announce their positions on the pliable issue. Third, the interest group's leader endorses one of the parties. Fourth, the voters update their beliefs about their personal desiderata based on their new information, and cast their ballots. Finally, the election determines the seat allocation and the legislature implements the policies indicated by the compromise rule.

The parties choose their positions on the pliable issue so as to maximize their vote counts. This means that party $A$ seeks to maximize $s$ in (5), while party $B$ seeks to minimize $s$. The parties need to evaluate not only the direct effects of their

\footnotetext{
${ }^{4}$ In computing (5) we assume that the diversity of views on the fixed policy issue is wide enough (i.e., the density $k$ is small enough) so that for every possible value of $\pi$ and every pair of pliable policies that might emerge in equilibrium, there is at least one insider and one outsider who votes for party $A$, and one from each category who votes for party $B$.

${ }^{5}$ In other words, the politicians and the group leader learn the members' true preferences, even as these preferences remain obscure to the members themselves. This assumption is meant to capture the politicians' and leader's superior understanding of the technical details of the policy issue.
} 
announcements, as reflected in the last parenthetical term in (5) and implicitly in $p$, but also the indirect effects that result from any induced impact on the behavior of the endorser and the ensuing changes in voters' perceptions. This is a complicated calculation requiring an understanding of the leader's endorsement rule (or strategy) and the process by which voters form their expectations about $\pi$. But before we even specify these elements, there are several observations we can make about an electoral equilibrium. First, party $A$ can ensure itself that $s$ is no less than $\frac{1}{2}+b$ by mimicking the pliable position of party $B$. Similarly, party $B$ can ensure itself that $s$ is no greater than $\frac{1}{2}+b$ by copying the position of party $A$. In a Nash equilibrium we must have $s$ no greater and no less than $\frac{1}{2}+b$; therefore, the equilibrium composition of the legislature reflects only the ex ante preferences of the voters. Now (5) implies that either the two pliable platforms are the same or that the pliable compromise exactly matches the expected $\pi$ in the aggregate population. We have thus established

Lemma 1 In any electoral equilibrium, (i) $s=\frac{1}{2}+b$, (ii) $p=\psi\left(\frac{1}{2}+b\right) p^{A}+$ $\left[1-\psi\left(\frac{1}{2}+b\right)\right] p^{B}$, and (iii) either $p^{A}=p^{B}$ or $p=n \mathcal{E}_{I}\left[\pi \mid \Omega_{I}\right]+(1-n) \mathcal{E}_{O}\left[\pi \mid \Omega_{O}\right]$.

We conclude this section with consideration of a benchmark case. Suppose that the interest-group leader makes no endorsement at all, or else one that is perceived as totally uninformative. As an example of the latter, voters might believe that the leader will endorse each party with probability $\frac{1}{2}$ regardless of $\pi_{I}$ and of the parties' positions. With an uninformative endorsement, the ex post information sets $\Omega_{I}$ and $\Omega_{O}$ are the same. It is reasonable to suppose, in this case, that insiders and outsiders will head to the polls with similar expectations about their interests on the pliable issue. This is because the prior distribution for both types has the same mean value of $\pi$, and both types update their priors based on the same new information (namely, the policy positions).

It is straightforward to construct a plausible PBE. Suppose that all voters retain their prior beliefs about $\pi$ no matter what platforms they observe; that is, without an informative endorsement to serve as a cue, $\mathcal{E}_{I}\left[\pi \mid \Omega_{I}\right]=\mathcal{E}_{O}\left[\pi \mid \Omega_{O}\right]=\frac{1}{2}$. With these expectations, the parties' maximization of their votes shares implies that there 
is a unique electoral equilibrium in which $s=\frac{1}{2}+b$ and both parties locate at the center of the pliable policy space. We describe this equilibrium more formally in

Proposition 2 Suppose there is no endorsement or one that is perceived to be uninformative. Then there exists a PBE in which: (i) $\mathcal{E}_{I}\left[\pi \mid \Omega_{I}\right]=\mathcal{E}_{O}\left[\pi \mid \Omega_{O}\right]=\frac{1}{2}$ for all possible information sets $\Omega_{I}$ and $\Omega_{O}$; and (ii) $p^{A}\left(\pi_{I}\right)=p^{B}\left(\pi_{I}\right)=\frac{1}{2}$ for all $\pi_{I} \in[0,1]$.

It is easy to verify that this is a PBE. With $\mathcal{E}_{I}\left[\pi \mid \Omega_{I}\right]=\mathcal{E}_{O}\left[\pi \mid \Omega_{O}\right]=\frac{1}{2}$, the voting rule in (4) implies that $s=\frac{1}{2}+b+2 a k\left(p-\frac{1}{2}\right)\left(p^{B}-p^{A}\right)$. This vote function generates a unique Nash equilibrium in which each party announces a pliable position of $\frac{1}{2}$. Moreover, the updating of beliefs satisfies Bayes' rule, because when the voters observe $p^{A}=p^{B}=\frac{1}{2}$ they obtain no information that would cause their posterior expectations to diverge from their priors. We will use this Hotelling-like equilibrium as a benchmark against which to assess the potential role of (informative) political endorsements. $^{6}$

\section{A Neutrality Result}

In this section we describe a situation in which interest-group endorsements are informative but not effective. This will set the stage for the succeeding sections, where we identify conditions under which endorsements can have real effects on political outcomes.

Suppose that outsiders perceive their interests on the pliable policy to be exactly complementary to those of insiders; i.e., they believe that "what's good for them is bad for us". In an economic model, such complementarity would apply to a purely redistributive policy; gains for one group of voters would have to come at the expense of the others. In our spatial model we can represent strict complementarity of interests by imposing a relationship between the realization of $\pi_{I}$ for insiders and the realization

\footnotetext{
${ }^{6}$ The equilibrium described in Proposition 1 is not the only PBE in our game. The parties might use their pliable positions to signal to voters the value of $\pi_{I}$ and the insiders might draw (consistent) inferences from these signals. However, signalling by parties is not the focus of this paper, so we choose to ignore this possibility in order to highlight the possible informational role of endorsements.
} 
of the mean value of $\pi$ among outsiders. In particular, let $\pi_{O}$ be the mean of $\pi$ among outsiders, and let the processes generating $\pi_{I}$ and $\pi_{O}$ be such that the population mean is constant and fixed at $\frac{1}{2}$; i.e.,

$$
n \pi_{I}+(1-n) \pi_{O}=\frac{1}{2} \text { for all } \pi_{I} \in[0,1]
$$

Under this assumption, the outsiders will understand that any movements of the pliable policy away from the center of the policy space that benefit insiders will, on average, be harmful to themselves. In this setting, information about $\pi_{I}$, such as might be conveyed by an endorsement, allows outsiders to update their beliefs about their own ideal policy, much as the insiders update theirs.

If the endorsement is observed by all voters, all will share the same information set $\Omega_{I}=\Omega_{O}=\Omega$. Insiders will use the endorsement to infer something about their likely ideal point; i.e., they will form expectations $\mathcal{E}_{I}\left[\pi_{I} \mid \Omega\right]$. Meanwhile, outsiders will be forming their own individual expectations about their personal ideal points, $\mathcal{E}_{O}[\pi \mid \Omega]$. In view of voters' understanding of the complementarity of interests as expressed in (6), it is plausible to suppose that the voters' beliefs will satisfy $n \mathcal{E}_{I}\left[\pi_{I} \mid \Omega\right]+(1-n) \mathcal{E}_{O}\left[\pi_{O} \mid \Omega\right]=\frac{1}{2}$. This would be true, for example, if every voter drew the same inference about $\pi_{I}$ from her observation of $p^{A}, p^{B}$ and the identity of the party that has been endorsed. In the event, we have the same circumstances of electoral competition as when the endorsement is uninformative. The average (expected) ideal point among all voters will be $\frac{1}{2}$. And so the parties will seek to maximize and minimize $s=\frac{1}{2}+b+2 k a\left(p-\frac{1}{2}\right)\left(p^{B}-p^{A}\right)$ with their choices of $p^{A}$ and $p^{B}$, respectively. In a Nash equilibrium, both parties locate in the center of the pliable policy space. And all of this is true no matter what the true value of $\pi_{I}$ happens to be. We have established

Proposition 3 Let the distribution of $\pi$ for outsiders conditional on the value of $\pi_{I}$ satisfy (6) and let the endorsement be observable to all voters. Then if all voters use the same mapping to update their beliefs about $\pi_{I}$ based on their observations, a PBE must have $p^{A}\left(\pi_{I}\right)=p^{B}\left(\pi_{I}\right)=\frac{1}{2}$ for all $\pi_{I} \in[0,1]$ regardless of the endorsement rule or strategy. 
Intuitively, the parties will have no reason to compete for the endorsement if they know that the goodwill they can generate among members of the interest group will be matched by an equal or greater loss of goodwill among the remaining voters. It will always pay for a party to move to the center, even if this means losing the interest-group's endorsement as a result.

Of course, Proposition 3 also suggests conditions under which an endorsement may not be so benign. First, the interests of the outsiders on the pliable issue may not be perfectly complementary to those of the insiders. At an extreme, the interests of the two types of voters may be completely independent; i.e., the conditional distribution of $\pi$ among outsiders might be the same for every value of $\pi_{I}$. Second, the endorsement might be heard by a greater proportion of insiders than of outsiders. Again, an extreme case would arise if the endorsement could be conveyed privately to the group's membership. We will adopt one or the other of these extreme assumptions in the next section, in order explore the potential policy effects of mechanical endorsement rules.

\section{$5 \quad$ Mechanical Endorsement Rules}

In this section we suppose that the interest group's leader employs a simple rule to choose the endorsee as a function of the announced positions of the two parties and the true interests of the membership in regard to the pliable policy. This rule is assumed to be common knowledge to the parties and the electorate.

We allow for a broad family of rules which we refer to as dividing-line rules. Before defining these, we need some additional notation. Let $E$ denote the recipient of the endorsement; either $E=A$ or $E=B$. Let $E_{\min }$ identify the party whose pliable position is smaller; i.e., $E_{\min } \equiv \arg \min _{A, B}\left\{p^{A}, p^{B}\right\}$. Similarly, $E_{\max } \equiv$ $\arg \max _{A, B}\left\{p^{A}, p^{B}\right\}$. Finally, let $g\left(p^{A}, p^{B}\right)$ be any continuous function with the property that $\min \left\{p^{A}, p^{B}\right\} \leq g\left(p^{A}, p^{B}\right) \leq \max \left\{p^{A}, p^{B}\right\}$ for all $p^{A}$ and $p^{B}$. Our definition of a dividing-line rule is as follows:

Definition (Dividing-Line Rule) If $p^{A} \neq p^{B}$ and either $g\left(p^{A}, p^{B}\right)<\pi_{I}$ or 
$g\left(p^{A}, p^{B}\right)=\pi_{I}=\max \left\{p^{A}, p^{B}\right\}$, then $E=E_{\max }$. If $p^{A} \neq p^{B}$ and either $g\left(p^{A}, p^{B}\right)>\pi_{I}$ or $g\left(p^{A}, p^{B}\right)=\pi_{I}=\min \left\{p^{A}, p^{B}\right\}$, then $E=E_{\min }$. Finally, if $p^{A}=p^{B}$ or if $\min \left\{p^{A}, p^{B}\right\}<g\left(p^{A}, p^{B}\right)=\pi_{I}<\max \left\{p^{A}, p^{B}\right\}$, then $E=A$ with probability one-half and $E=B$ with probability one-half.

Intuitively, the function $g(\cdot)$ determines a dividing line between the announced positions of the two parties. If the ideal point $\pi_{I}$ of group members lies above the dividing line, then the endorser taps the party whose pliable policy position is higher. If the ideal point falls below the dividing line, then the endorser names the party whose pliable position is lower. If $\pi_{I}$ falls right on the dividing line and (exactly) one of the parties has announced the group's ideal position, then this party is endorsed. Otherwise, each party receives the endorsement with probability one-half. An example of such a rule is $g\left(p^{A}, p^{B}\right)=\left(p^{A}+p^{B}\right) / 2$. This rule sets the dividing line midway between the pliable positions of the two parties and so identifies the party whose pliable position is closer to the interest group's ideal.

We will now describe a PBE that applies for all rules in this class. Assume first that the interests of the outsiders happen to be orthogonal to those of the interestgroup members; i.e., the conditional distribution of $\pi$ for any outsider is independent of nature's choice of $\pi_{I}$. Then, obviously, the endorsement gives the outsiders no useful information. Insiders, meanwhile, will use the information conveyed by the endorsement to update their beliefs about their interests on the pliable issue.

The description of an equilibrium must specify not only the policy positions adopted by the parties, but also how voters update their beliefs in response to the events they witness. The updating of beliefs by insiders can be best understood with the aid of Figure 1. The figure shows two possible policy positions for the two political parties. We have placed party $B$ at the center of the policy spectrum $\left(p^{B}=\frac{1}{2}\right)$ to facilitate later discussion. Suppose party $A$ has announced some position $p^{A}<\frac{1}{2}$, as shown. Between the two policies is the dividing line $g\left(p^{A}, p^{B}\right)$. If the interest-group leader knows that the group's ideal point $\pi_{I}$ lies to the left of $g\left(p^{A}, p^{B}\right)$, she will endorse party $A$. Seeing this endorsement, the insiders will be able to rule out the possibility that $\pi_{I}>g\left(p^{A}, p^{B}\right)$. This information allows the insiders to form a new 
Assumption $2 \quad n \leq \min \left[\frac{\psi\left(\frac{1}{2}+b\right)}{\mathcal{M}}, \frac{1-\psi\left(\frac{1}{2}+b\right)}{\mathcal{M}}, \frac{1}{2}\right]$

where $\mathcal{M} \equiv \max _{x \in[0,1]} M^{\prime}(x)$. We note that $\mathcal{M}=\frac{1}{2}$ when priors are uniform, $\mathcal{M}=\frac{2}{3}$ when they are triangular, and that $\mathcal{M}$ always is a finite number.

We are now ready to describe a PBE in which political endorsements play a role in policy determination. In this equilibrium, the parties compete for the interest group's endorsement by shifting their positions on the pliable issue (relative to the benchmark outcome) in the direction beneficial to the group's members. Our statement of the proposition in the text indicates only the platforms and policy outcomes that are observed in the equilibrium. The technically-minded reader may consult the appendix for a fuller statement of the proposition which provides the details of the supporting beliefs.

Proposition 4 Let the conditional distribution of $\pi$ for outsiders be independent of $\pi_{I}$ and let the endorsement be observable to all voters. Suppose that the endorsement obeys a dividing-line mule and that Assumptions 1 and 2 are satisfied. Then there exists a PBE in which

(i) $p^{A}\left(\pi_{I}\right)=p^{B}\left(\pi_{I}\right)=p\left(\pi_{I}\right)=\left\{\begin{array}{cr}\gamma & \text { for } 0 \leq \pi_{I} \leq \gamma \\ \pi_{I} & \text { for } \gamma<\pi_{I}<1-\gamma ; \\ 1-\gamma & \text { for } 1-\gamma \leq \pi_{I} \leq 1\end{array}\right.$

(ii) $q=1-\psi\left(\frac{1}{2}+b\right)$

The proposition is proved in the appendix. Here we discuss its meaning and provide intuition.

In the equilibrium described by Proposition 3 , the parties compete vigorously for the endorsement, but only "up to a point." If the interest group members truly are moderates - that is, if they hold an ideal policy position not too far from $\frac{1}{2}-$ then the parties converge on exactly this position, and the policy outcome fulfills the group's ideal. However, if the group members are more extreme in their preferences, the parties will not go all the way to satisfying their wishes. In fact, the parties do not announce positions less than $\gamma$ (or greater than $1-\gamma$ ), no matter how extreme 
the group's tastes. The pliable policy outcome is at $\gamma$ whenever $\pi_{I} \leq \gamma$, and at $1-\gamma$ whenever $\pi_{I} \geq 1-\gamma$, and thus is not responsive to $\pi_{I}$ in these ranges. The larger is the interest group, the smaller is $\gamma$, and so the larger is the range of values of $\pi_{I}$ for which the group attains its ideal.

To understand the basis for this equilibrium, let us begin at the benchmark. Suppose both parties were contemplating positions at the center of the policy spectrum, and now let party $A$ entertain a possible deviation to the position marked $p^{A}$ in Figure 1. This deviation would win party $A$ the endorsement of the interest group. The group's members would update their beliefs, now recognizing that $\pi_{I} \leq g\left(p^{A}, \frac{1}{2}\right)$, and would calculate an updated expected value of $\pi_{I}$ equal to $M\left[g\left(p^{A}, \frac{1}{2}\right)\right]$. For $p^{A}$ sufficiently close to $\frac{1}{2}$, this expected value of $\pi_{I}$ would be less than $p^{A}$. But with $\mathcal{E}_{I}\left(\pi_{I}\right)<p^{A}<p^{B}$, the voting rule (4) implies that party $A$ captures more than the fraction $\frac{1}{2}+b$ of the group member's votes. The deviation wins party $A$ votes among the insiders, because by capturing the leader's endorsement the party induces the group members to believe that its pliable position better serves their interests. At the same time, the deviation costs party $A$ votes among outsiders, because these voters retain their belief that their ideal pliable policy has an expected value of $\frac{1}{2}$. However, the vote gain among insiders outweighs the loss among outsiders, at least for deviations close enough to $p^{B}=\frac{1}{2}$. For $p^{A}$ close to $\frac{1}{2}$, party $A$ loses only a "few" votes among outsiders, because the parties' pliable positions are close to one another, and both are close to the outsiders' (expected) ideal. The vote gain among insiders is an order of magnitude larger, because although they too see the two platforms as similar, they see both as relatively distant from their (updated) ideal point at $\mathcal{E}_{I}\left(\pi_{I}\right)$. In other words, the perceived utility difference between the two pliable platforms is substantially larger for insiders than for outsiders, and so more of them will be inclined to shift their votes to the party whose pliable policy they prefer.

Now two things can happen, according to the proposition. First, for moderate values of $\pi_{I}$, both parties will depart from the benchmark to announce positions exactly at $\pi_{I}$. Second, for more extreme values of $\pi_{I}$, the parties will announce positions at $\gamma$ (or, symmetrically, at $1-\gamma$, if $\pi_{I}>\frac{1}{2}$ ) and evidently neither will have 
an incentive to deviate further. Let us consider each possibility in turn.

With a moderate value of $\pi_{I}$ such as that depicted in Figure 1, suppose party $A$ anticipates that its rival will announce a pliable position of $p^{B}=\pi_{I}$. What then are the incentives facing this party? If it also were to adopt $\pi_{I}$ as its pliable position, then whatever the (random) endorsement by the group leader, party $A$ would capture the fraction $\frac{1}{2}+b$ of the votes of both insiders and outsiders. This is shown in Figure 2 , which plots the vote counts for party $A$ among each group and in toto as functions of the position taken by party $A$ (assuming $p^{B}=\pi_{I}$ ). Another possibility is that party $A$ might opt for a position $p^{A}<\pi_{I}$. Clearly, it would then win less than $\frac{1}{2}+b$ of the outsiders' $1-n$ votes. These voters perceive an expected ideal of $\frac{1}{2}$, and so they prefer the pliable platform of party $B$ to that of party $A$ when $p^{A}<p^{B}<\frac{1}{2}$. Moreover, the announcement by party $A$ of a platform $p^{A}<\pi_{I}$ when $p^{B}=\pi_{I}$ would cause the group leader to endorse party $B$. The group members would infer that $\pi_{I} \geq g\left(p^{A}, \pi_{I}\right)$ and would calculate a new expectation of $\pi_{I}$ greater than $p^{B}$. Then, since $\mathcal{E}_{I}\left(\pi_{I}\right)>p^{B}>p^{A}$, party $A$ would capture fewer than the fraction $\frac{1}{2}+b$ of their votes. In short, the announcement by party $A$ of a platform $p^{A}<\pi_{I}$ yields fewer than $\frac{1}{2}+b$ of the votes of both insiders and outsiders, and so is dominated by the announcement of $p^{A}=\pi_{I}$.

A more interesting possibility is that party $A$ might locate its policy slightly above $\pi_{I}$, closer to the center of the policy space. This would make the party more attractive than its rival to outsiders (with their expected ideal points at $\frac{1}{2}$ ), and so party $A$ would capture more than the fraction $\frac{1}{2}+b$ of their votes, as depicted in the figure. But the party again would sacrifice the endorsement of the interest group. With the leader endorsing party $B$, and $p^{A}>p^{B}$, insiders would interpret the endorsement to mean $\pi_{I} \leq g\left(p^{A}, \pi_{I}\right)$. They would calculate $\mathcal{E}_{I}\left[\pi_{I} \mid \pi_{I} \leq g\left(p^{A}, \pi_{I}\right)\right]=$ $M\left[g\left(p^{A}, \pi_{I}\right)\right]<p^{B}$. Thus, the move would cost party $A$ votes among insiders, relative to the alternative of locating exactly at $\pi_{I}$. Herein lies the trade-off confronting party A.

So which is bigger, the gain in votes among outsiders or the loss in votes among insiders? Equation (5) tells us that, with $p^{A}>p^{B}$, the aggregate vote share for 
party $A$ exceeds $\frac{1}{2}+b$ if and only if the anticipated policy compromise $p$ is below the population mean expected value of $\pi$. With $p^{A}$ and $p^{B}$ both close to $\pi_{I}$, the anticipated compromise also is close to $\pi_{I}$. But the population mean expected value of $\pi$ must be greater than $\pi_{I}$, in view of the definition of $\gamma$ and the fact that $\pi_{I}>\gamma$. It follows that party $A$ attracts more total votes by locating at $\pi_{I}$ than by locating slightly to the right of $\pi_{I}$; the gain in outsider votes from deviating slightly to the right does not compensate the loss in insider votes. ${ }^{8}$ The best response to $p^{B}=\pi_{I}$ is for party $A$ to announce $\pi_{I}$, and both parties converge on the interest group's ideal pliable position.

Now consider the case where the interest group's preferences are more extreme; i.e., $\pi_{I}<\gamma$. Then, if party $B$ were located at $\pi_{I}$, party $A$ could improve its vote count (relative to locating at $\pi_{I}$ as well) by locating just to the right of its rival. This move would cost the party the interest group's endorsement, but the ensuing loss of insider votes would be more than compensated by the gain in outsider votes. The definition of $\gamma$ ensures that this is so, because with $\pi_{I}<\gamma$, the updating of beliefs that attends the endorsement of party $B$ leaves the population mean expected value of $\pi$ less than $\pi_{I}$. But with $p^{A}>p^{B}$ and both close to $\pi_{I}$, this implies by (5) a vote share for party $A$ in excess of $\frac{1}{2}+b$. Both parties will have an incentive to move from $\pi_{I}$ toward the center, when $\pi_{I}$ is extreme.

How far will they move? If party $B$ is located anywhere to the left of $\gamma$, the above argument establishes that party $A$ can capture more than $\frac{1}{2}+b$ of the seats by locating just to its right. Lemma 1 rules this out as a possible equilibrium outcome. Similarly, if party $B$ is located to the right of $\gamma$, party $A$ can capture more than $\frac{1}{2}+b$ of the seats by locating just to its left. This situation too cannot arise in equilibrium. The only remaining possibility is that party $B$ locates exactly at $\gamma$, in which case it is a best response for party $A$ to follow suit. This concludes our discussion of the equilibrium when the interests of outsiders are orthogonal to those of the interest-group members.

\footnotetext{
${ }^{8}$ The argument against deviations to points far to the right of $\pi_{I}$ is somewhat more technical and requires that $n \mathcal{M}<\psi\left(\frac{1}{2}+b\right)$, as stipulated by Assumption 2. The argument is provided in the appendix.
} 
Let us return briefly to the case where the interests of the outsiders are perfectly complementary to those of the insiders. Suppose now that the outsiders do not observe the group leader's endorsement. The main point to be made is that a PBE very similar to the one described in Proposition 3 exists in this case as well. In this equilibrium, the platforms are the same as those specified in Proposition 3, as are the updated beliefs of insiders. Only the beliefs of the outsiders are different. ${ }^{9}$

We have established that endorsements by special interest groups can affect policy outcomes. When the interests of group members are not perfectly complementary to those of outsiders, the parties will compete for an endorsement knowing that its value outweighs the cost of alienating some marginal supporters. Similarly, when outsiders do not observe the leader's pronouncement, the parties may have incentive to pander to the group's interests at the expense of unwitting outsiders. In either case, the parties grant a relatively centrist group its first-best pliable platform while tilting somewhat in the direction of a group with more extreme desires.

It is worth emphasizing that the political equilibrium described in Proposition 3 is robust to the particulars of the endorsement rule; the same platforms and policies can emerge for all rules in the broad class of dividing-line rules.

\section{Welfare}

We devote this section to analyzing the normative properties of the equilibrium described by Proposition 3.

Conditional on the value of $\pi_{I}$ the utility of a representative group member is given by

$$
u_{I}\left(p, q \mid \pi_{I}\right)=-a\left(p-\pi_{I}\right)^{2}+\beta q .
$$

An outsider has a conditional distribution for $\pi$ that is independent of $\pi_{I}$ under the conditions of Proposition 3. Letting $\varphi(\pi)$ represent the density of this conditional distribution, an outsider's expected utility equals

$$
u_{O}\left(p, q \mid \pi_{I}\right)=-a \int_{0}^{1}(p-\pi)^{2} \varphi(\pi) d \pi+\beta q=-a\left(p-\frac{1}{2}\right)^{2}-a \operatorname{var}\left(\pi_{O}\right)+\beta q,
$$

\footnotetext{
${ }^{9}$ Our working paper, Grossman and Helpman (1996b), describes the supporting beliefs.
} 
whenever $\pi_{I}$ is less than $\gamma_{c}$ or greater than $1-\gamma_{c}{ }^{10}$

Proposition 5 Let the conditional distribution of $\pi$ for outsiders be independent of $\pi_{I}$ and let Assumptions 1 and 2 be satisfied. Then for all values of $\pi_{I}$, the utility of insiders is higher and the expected utility of outsiders is lower in the equilibrium described by Proposition 3 than in the benchmark equilibrium. Aggregate welfare is higher in the equilibrium described by Proposition 3 if and only if $0 \leq \pi_{I}<\gamma_{c}$ or $1-\gamma_{c}<\pi_{I} \leq 1$.

It is also interesting to compare how group members fare in the equilibrium described by Proposition 3 relative to the utility they would achieve in a hypothetical setting in which they were fully informed. In the latter scenario each group member would vote using the rule indicated by (4), except that the true value of $\pi$ would stand in the place of its expected value. Assuming that outsiders had interests independent of the group members' interests, and that $\mathcal{E}_{O}\left(\pi \mid \Omega_{O}\right)=\frac{1}{2}$, the parties' vote shares would vary with their announced platforms according to

$$
s=\frac{1}{2}+b+2 k a\left(p-n \pi_{I}-\frac{1-n}{2}\right)\left(p^{B}-p^{A}\right) \text {. }
$$

Then the parties would set identical platforms of

$$
p^{A}\left(\pi_{I}\right)=p^{B}\left(\pi_{I}\right)=n \pi_{I}+\frac{1-n}{2}
$$

\footnotetext{
${ }^{10}$ To find this critical value $\gamma_{c}$ observe that (9) and (10) imply that for $\pi_{I} \leq \gamma$ aggregate welfare is higher in the equilibrium of Proposition 3 than in the benchmark equilibrium if and only if

$$
n\left[\left(\frac{1}{2}-\pi_{I}\right)^{2}-\left(\gamma-\pi_{I}\right)^{2}\right]>(1-n)\left(\frac{1}{2}-\gamma\right)^{2} .
$$

For ideal points $\pi_{I}$ close to $\gamma$ this condition is violated, because $n<1-n$. Therefore, the benchmark equilibrium is preferable for such values of $\pi_{I}$. But the left-hand side of (11) is declining in $\pi_{I}$ (because $\gamma<1 / 2$ ). Moreover, the fact that the right-hand side of (8) is increasing in $\gamma$ and obtains the value $\frac{1-n}{2}$ at $\gamma=0$ implies that the $\gamma$ which solves (8) is greater than $\frac{1-n}{2}$ and therefore greater than $\frac{1}{2}-n$. But $\gamma>\frac{1}{2}-n$ in turn implies that the the inequality (11) is satisfied for $\pi_{I}=0$. Therefore, there must exist a $\gamma_{c}$ between zero and $\gamma$ such that (11) holds for all $0 \leq \pi_{I}<\gamma_{c}$. By symmetry, it also holds for all $1-\gamma_{c}<\pi_{I} \leq 1$.
} 


\section{Strategic Endorsements}

Until now, we have not treated the leader of the interest group as a player in the political game. Rather, the leader was assumed to follow a simple mechanical rule, signalling to the membership where their interests stand in relation to the pliable platforms of the two parties. If the true value of $\pi_{I}$ was above a dividing line between the parties' positions, the leader endorsed the party with the higher policy stance; otherwise he endorsed the party with the lower stance. But what if the leader were to behave strategically?

The reader might be wondering at this point why the interest-group leader would have any incentive to behave strategically vis-à-vis the members of his group. After all, the leader presumably has the best interests of the members at heart. An incentive for strategic behavior arises nonetheless from the members' disparate views on the fixed policy issue. No matter what his policy objectives, the leader may wish that all members of his group would vote for the same party, so as to push the compromise policy as close to his target outcome as possible. But the group members, if wellinformed, would not vote as a bloc. Rather, those with a strong affinity for the ideological position of party $A$ would vote for that party notwithstanding the negative

than to be forced to rely on the endorsement as a cue. Group members view $\pi_{I}$ as being drawn from a distribution $F\left(\pi_{I}\right)$ with support $[0,1]$. We can use this distribution and the policy outcomes for each value of $\pi_{I}$ to calculate their expected utility under each regime (full information and endorsement). Doing so, we find that expected utility is higher with full information. Of course, it may be costly for the members to become fully informed, which is why they might rely on the endorsement for information in the first place. Moreover, it can be shown that, even if the group's leader could transmit more detailed information than just an endorsement, such a leader would have an incentive to misreport $\pi_{I}$. Indeed, a leader seeking to maximize her group's welfare would always exaggerate her report of the group's ideal, claiming $\pi_{I}=0$ when the group would benefit from additional votes for the party with the lesser-most pliable position, and $\pi_{I}=1$ otherwise. Unless there existed a mechanism to enforce truthful reporting by the leader, the members could not rely on their central organization to become fully informed. In fact, reasoning similar to that employed by Crawford and Sobel (1981) can be used to show that the equilibrium described by Proposition 3 remains an equilibrium in a "cheap-talk" game in which the interest-group leader is able to report costlessly the exact value of $\pi_{I}$ (or any other information). 
effect of their votes on the aggregate well-being of the group. Similarly, those with a strong preference for the fixed position of party $B$ would vote unfailingly for that party. The leader then may behave strategically in an attempt to induce as many individuals as possible to caste their ballots in the collective interest.

We suppose here that leader of the interest group is concerned only with the pliable policy outcome. ${ }^{13}$ The leader seeks to maximize

$$
U=-a\left(p-\pi_{I}\right)^{2}
$$

which is the utility that each member derives from the realization of the pliable policy. With this objective, the leader chooses whom to endorse with an eye toward minimizing the distance between the anticipated policy outcome and the group's ideal point. In order to decide whom to endorse, the leader must gauge how his backing will be interpreted by the group's members. At the same time, the members' interpretation presumably depends on the incentives they judge for their leader.

There is a surprisingly simple solution to this inference problem. We can show that there always exists a particular dividing-line rule with desirable consistency properties. Namely, if group members suspect their leader of following this particular rule, they can (consistently) update their beliefs in the manner specified by Proposition 3. And if the leader anticipates this updating procedure, the indicated rule indeed maximizes $U(\cdot)$ in (12). This means that the parties can (consistently) forecast this rule, and set their platforms in its full anticipation. In other words, the platforms and policies described in Proposition 3 remain PBE outcomes when the group leader behaves strategically.

The appendix contains a proof of the following proposition:

Proposition 6 Let the conditional distribution of $\pi$ for outsiders be independent of $\pi_{I}$ and let the endorsement be observable to all voters. Suppose that the interest-group leader issues his endorsement to maximize (12) and that Assumptions 1 and 2 are satisfied. Then there exists a PBE with a dividing-line rule $g(\cdot)$ such that

\footnotetext{
${ }^{13}$ Our conclusions in this section are not sensitive to this assumption. We could alternatively have the leader maximizing the aggregate welfare of group members, including the utility they derive from the fixed policy outcome.
} 
(i) voters expect the leader to use the dividing-line rule $g(\cdot)$;

(ii) $g(\cdot)$ is optimal for the interest-group leader given voters' beliefs;

(iii) voters' beliefs and parties' platforms are exactly as in Proposition 3.

Here we will try to explain why the result is true.

Suppose that members of the interest group suspect their leader of using some particular dividing-line rule, say the one described by the function $g^{\circ}\left(p^{A}, p^{B}\right)$. Suppose further that, upon hearing the policy stances and the leader's endorsement, these individuals update their beliefs about $\pi_{I}$ as we have described before. In particular, an endorsement of the party with the upper-most pliable policy leads members to rule out the possibility that $\pi_{I} \leq g^{\circ}\left(p^{A}, p^{B}\right)$, while an endorsement of the party with the lower-most pliable policy leads members to rule out $\pi_{I} \geq g^{\circ}\left(p^{A}, p^{B}\right)$. Beyond that, the updating applies Bayes' Rule. Then, for each pair of platforms $p^{A}$ and $p^{B}$ an insider seeing an endorsement of one party or the other will form an expectation $\mathcal{E}_{I}\left[\pi_{I} \mid p^{A}, p^{B}, E\right]$ which she will use in deciding what lever to pull in the voting booth.

Having specified how an endorsement will be interpreted, we know how each insider will vote when the platforms are $p^{A}$ and $p^{B}$ and when the leader has announced support for one party or the other. Suppose that outsiders retain their prior belief that their expected ideal position is $\frac{1}{2}$ whenever the pliable platforms of the two parties diverge. Then the leader can calculate the votes that each party would garner were he to endorse party $A$ upon hearing the platforms $p^{A}$ and $p^{B}$, and also the votes that each would receive were he instead to tap party $B$. Since he can calculate the vote tallies that ensue from his actions, the leader also can calculate the policy compromises that would attend an endorsement of either party. One of these outcomes gives higher welfare according to the objective function $U(\cdot)$ in (12). This is the endorsement that the strategic leader will make when the platforms are $p^{A}$ and $p^{B}$.

We argue now that the endorsement procedure just described is itself a divingline rule. For any two possible policy outcomes, the utility function $U(\cdot)$ in (12) is maximized by the choice of the policy that is closer to $\pi_{I}$. So, if the endorsement of party $A$ would lead to a compromise outcome of, say, $\tilde{p}^{A}$, whereas the endorsement of 
party $B$ would lead to an outcome of $\tilde{p}^{B}>\tilde{p}^{A}$, then the leader would endorse party $A$ if and only if $\pi_{I}$ fell below the mid-point between $\tilde{p}^{A}$ and $\tilde{p}^{B}$. But notice that this midpoint is itself between the platforms $p^{A}$ and $p^{B}$, since each of the two compromises $\tilde{p}^{A}$ and $\tilde{p}^{B}$ lies between the two platforms. We conclude that, for each platform pair $p^{A}$ and $p^{B}$, the leader's endorsement reflects a comparison of the ideal point $\pi_{I}$ and a point between the two platforms. But that is precisely what characterizes a dividing-line rule.

We have argued that when members anticipate an arbitrary endorsement rule $g^{\circ}(\cdot)$, the maximizing leader opts for a particular dividing-line rule, say $\tilde{g}(\cdot)$. Each suspected endorsement rule gives rise to some specific optimal endorsement rule. But there is, as yet, no guarantee of consistency between the two. But what if there existed a dividing-line rule that, when anticipated by members, gave rise to optimizing behavior by the leader of exactly the same form? Then such a rule would have the desired consistency property. Technically speaking, we need a fixed point in the mapping from $g^{\circ}$ to $\tilde{g}$.

The proof of Proposition 5 establishes the existence of such a fixed point by construction. For each pair of platforms, let the insiders suspect a "dividing point" specific to that pair. If this point were equal to the lesser of the two platforms, the optimal dividing point for the leader-which we have argued always lies between $p^{A}$ and $p^{B}$-would be above the suspected dividing point. If the suspected dividing point were equal to the greater of the two platforms, the optimal dividing point would be below the suspected point. Since the optimal point can be shown to be a continuous function of the suspected point, there must be a value for which the two are equal. Repeating this procedure for every possible platform pair generates the desired dividing-line rule, $g\left(p^{A}, p^{B}\right)$.

As endorsers, strategic leaders do no better for their charges than mechanical leaders. Once the members take into account their leader's incentives, the leader loses his ability to manipulate the group. What remains is only the information that can be conveyed in a simple, binary message. 


\section{Multiple Interest Groups}

When there is only one interest group, the parties can seek the group's endorsement with only the concern that their catering might alienate some of the unaffiliated voters. But when there are several such groups, the parties will know that by making concessions to one group they may lose the endorsements of some others. We examine here the competition for endorsements with multiple special interest groups.

Let there be $S$ groups indexed by $i$ with a fraction $n_{i}$ of the voters in group $i$. Each voter belongs to at most one interest group. Denote the ideal pliable policy for a member of group $i$ by $\pi_{i}$ and assume that its cumulative distribution is $F_{i}\left(\pi_{i}\right)$ with support $[0,1]$. The ideal points for different interest groups are independently distributed. Outsiders have ideal points $\pi$ conditional on $\left\{\pi_{1}, \ldots, \pi_{S}\right\}$ that are symmetrically distributed and independent of $\left\{\pi_{1}, \ldots, \pi_{S}\right\}$, with mean $\frac{1}{2}$.

We assume that aggregate membership in interest groups is not too large. In particular, we adopt

Assumption $3 \sum_{i \in S} n_{i} \leq \min \left[\frac{\psi\left(\frac{1}{2}+b\right)}{\mathcal{M}}, \frac{1-\psi\left(\frac{1}{2}+b\right)}{\mathcal{M}}\right]$.

Note that $S$ here represents the set of interest groups, as well as their number.

Suppose the groups employ (possibly different) mechanical endorsement rules. The leader of group $i$ compares the location of $\pi_{i}$ with the point $g_{i}\left(p^{A}, p^{B}\right)$. He taps one party or the other according to the prescription in our earlier definition of a dividing-line rule. The endorsements are issued simultaneously, after the parties have chosen their policy stances.

The competition for endorsements involves the parties in trading off the sizes of the various groups of voters. By deviating upward from a conjectured equilibrium, for example, a party could capture the endorsements of groups with ideal points above the dividing line(s) between the positions, but would lose the endorsements of groups with ideal points below the dividing line(s). This would be beneficial to the party if the groups with ideal points above the line were predominantly large groups, while those with ideal points below the line were smaller groups. In equilibrium, of course, no beneficial deviations are possible. In the equilibrium (as well as out of 
equilibrium) most voters do not learn the true location of their group's ideal point. They observe only the positions of the two parties and the list of endorsements. Their own leader's endorsement may allow them to rule out some of the possibilities for their true interests on the pliable issue, but unless the platforms somehow reveal their own first-best, they are left with residual uncertainty. As a result, the true preferences of the voters play only a secondary role in determining the equilibrium policy platforms and the policy outcome.

Let us describe a PBE, first informally, and then in a more formal statement. There are two possible equilibrium configurations, exactly one of which must exist for any particular realization of $\left\{\pi_{1}, \ldots, \pi_{S}\right\}$. In either configuration the parties announce the same pliable platforms, which then match the policy compromise. Suppose first that we can partition the interest groups into two sets, $\hat{h}$ and $\hat{l}$, with the following properties. First, all groups $i$ in set $\hat{h}$ ( $h$ for "high") have ideal points $\pi_{i}$ that are higher than the equilibrium pliable policy. Second, all groups $i$ in set $\hat{l}$ ( $l$ for "low") have ideal points $\pi_{i}$ that are lower than the equilibrium pliable policy. Third, there exists a policy $\hat{p}$ that is strictly higher than the highest $\pi_{i}$ in $\hat{l}$ and strictly lower than the lowest $\pi_{i}$ in $\hat{h}$ such that ${ }^{14}$

$$
\hat{p}=\sum_{i \in \hat{l}} n_{i} M_{i}(\hat{p})+\sum_{i \in \hat{h}} n_{i} N_{i}(\hat{p})+\left(1-\sum_{i \in S} n_{i}\right) \frac{1}{2} .
$$

Then the parties both announce $\hat{p}$ as their equilibrium platforms and in equilibrium all groups endorse randomly. If one party were to deviate from $\hat{p}$, say by announcing a $p^{j}$ slightly higher than $\hat{p}$, then this party would win the endorsement of all groups in $\hat{h}$ while losing the endorsement of all groups in $\hat{l}$. Members of group $i$ in $\hat{h}$ would update their beliefs so as to imagine that their group's members had an ideal point drawn from a distribution with density $f_{i}\left(\pi_{i}\right) /\left[1-F_{i}\left(g_{i}\left(p^{A}, p^{B}\right)\right)\right]$ and support $\left[g_{i}\left(p^{A}, p^{B}\right), 1\right]$. Similarly, members of group $i$ in $\hat{l}$ would update their beliefs so that $\pi_{i}$ was seen distributed with density $f_{i}\left(\pi_{i}\right) / F\left(g_{i}\left(p^{A}, p^{B}\right)\right)$ on $\left[0, g_{i}\left(p^{A}, p^{B}\right)\right]$. The value of $\hat{p}$ has been calculated so that this deviation, as well as the alternative deviation to a platform below the equilibrium policy, is unprofitable.

\footnotetext{
${ }^{14}$ We define $M_{i}(z)$ and $N_{i}(z)$ analagously to $M(z)$ and $N(z)$; i.e., $M_{i}(z) \equiv \int_{0}^{z} x f_{i}(x) d x / F_{i}(z)$ and $N_{i}(z) \equiv \int_{z}^{1} x f_{i}(x) d x /\left[1-F_{i}(z)\right]$.
} 
Now suppose that no such partition of the parties and identification of $\hat{p}$ is possible. Then it will be possible to divide the groups into three subsets: $\hat{h}$ and $\hat{l}$ are as before, while $\hat{m}$ (for "middle") is a set that is likely to have only one member. The groups $i \in \hat{m}$ have the same ideal point of $\pi_{i}$. In this case, the parties' platforms coincide with the ideal point for members of each interest group in $\hat{m}$. Moreover, $\hat{p}=\pi_{i}$ for $i \in \hat{m}$ is such that

$$
\hat{p} \geq \sum_{i \in \hat{\mathbb{L} \cup \dot{m}}} n_{i} M_{i}(\hat{p})+\sum_{i \in \hat{h}} n_{i} N_{i}(\hat{p})+\left(1-\sum_{i \in \mathcal{S}} n_{i}\right) \frac{1}{2}
$$

and

$$
\hat{p} \leq \sum_{i \in \hat{l}} n_{i} M_{i}(\hat{p})+\sum_{i \in \hat{h} \cup \hat{m}} n_{i} N_{i}(\hat{p})+\left(1-\sum_{i \in S} n_{i}\right) \frac{1}{2} .
$$

Here a party would lose the endorsement of all groups in $\hat{h}$ and $\hat{m}$ were it to change its platform to one slightly below $\hat{p}$, while it would lose the endorsement of all groups in $\hat{l}$ and $\hat{m}$ were it to deviate in the opposite direction.

We now state more formally the following proposition:

Proposition 7 Let the conditional distribution of $\pi$ for outsiders be independent of $\left\{\pi_{1}, \ldots, \pi_{S}\right\}$ and let the distribution of $\pi_{i}, i \in S$, be independent of $\pi_{j}$ for all $j \in S$, $j \neq i$, with the cumulative distribution $F_{i}\left(\pi_{i}\right)$ on $[0,1]$. Suppose that all endorsements obey dividing-line rules, that endorsements are observable to all voters, that each $F_{i}\left(\pi_{i}\right), i \in S$, satisfies Assumptions 1, and that Assumption 3 is also satisfied. Then theire exists a PBE in which either groups can be partitioned into sets $\hat{h}$ and $\hat{l}$ such that $\pi_{i}>\hat{p}$ for all $i \in \hat{h}$ and $\pi_{i}<\hat{p}$ for all $i \in \hat{l}$, where $\hat{p}$ is defined as in (13), in which case $p^{A}=p^{B}=\hat{p}$, or groups can be partitioned into sets $\hat{h}, \hat{m}$, and $\hat{l}$ such that $\pi_{i}>\hat{p}$ for all $i \in \hat{h}, \pi_{i}<\hat{p}$ for all $i \in \hat{l}, \hat{p}=\pi_{i}$ for all $i \in \hat{m}$, and $\hat{p}$ satisfies inequalities (14) and (15), in which case $p^{A}=p^{B}=\pi_{i}$ for all $i \in \hat{m}$.

This proposition, which is supported by beliefs analogous to those that support the equilibrium described by Proposition 3, is proved in the appendix.

Notice that Proposition 6 is a proper generalization of Proposition 3. If there is only one interest group, this group must be either the sole member of $\hat{h}$ (with sets 
$\hat{m}$ and $\hat{l}$ empty), the sole member of $\hat{l}$ (with sets $\hat{m}$ and $\hat{h}$ empty), or the sole member of $\hat{m}$ (with sets $\hat{h}$ and $\hat{l}$ empty). Also, the right-hand side of (13) equals $\gamma$ when the one group is in $\hat{l}$, and it equals $1-\gamma$ when the one group is in $\hat{h}$. When the group is in $\hat{m}$, it gets its first-best policy as an equilibrium outcome. The appendix shows, moreover, that there is another sense in which the equilibrium with multiple lobbies generalizes Proposition 3. It is possible to define a parameter $\Gamma$, which solves

$$
\Gamma=\sum_{i \in S} n_{i} M_{i}(\Gamma)+\left(1-\sum_{i \in S} n_{i}\right) \frac{1}{2},
$$

such that if all interest groups have ideal points $\pi_{i} \leq \Gamma$, then the parties set their pliable platforms at $\Gamma$, while if all groups have ideal points $\pi_{i} \geq 1-\Gamma$, then the parties set their pliable platforms at $1-\Gamma$. Finally, if some groups have ideal points in the range $(\Gamma, 1-\Gamma)$, then the pliable platforms will fall between the ideal points of the two most-extreme interest groups.

A simple example might serve to clarify some of the implications of Proposition 6. Suppose there are only two equal-size interest groups with uniform densities $f_{i}\left(\pi_{i}\right)=$ 1 on $[0,1]$. Order the groups so that $\pi_{1}<\pi_{2}$. There are three types of equilibrium configurations that are consistent with Proposition 6.

First, if $\pi_{1}<\frac{1}{2}<\pi_{2}$, then (13) is satisfied with $\hat{l}=\{1\}, \hat{h}=\{2\}$, and $p^{A}=p^{B}=$ $\hat{p}=\frac{1}{2}$. In this case, the two equal-sized groups completely neutralize one another, even though their interests may not be symmetrically placed about the center. In the equilibrium, were a party to edge toward one group's median ideal point, it would gain that group's endorsement, but lose the endorsement of the other as well as some of the outsider's votes. The deviation would not be profitable given that the groups are of equal size.

Second, if $\pi_{1}<\pi_{2}<\Gamma$, then (13) is satisfied with $\hat{l}=\{1,2\}, \hat{h}=\emptyset$ and $p^{A}=$ $p^{B}=\hat{p}=\Gamma$. Similarly, if $\pi_{2}>\pi_{1}>1-\Gamma$, then (13) is satisfied with $\hat{l}=\emptyset, \hat{h}=$ $\{1,2\}$ and $p^{A}=p^{B}=\hat{p}=1-\Gamma$. Here, the interest groups both have extreme and qualitatively similar preferences and the parties compete for their endorsements. But the competition is limited by the parties' concern about losing too many of the outsider's votes. 
Finally, if $\pi_{1}<\pi_{2}<\frac{1}{2}$ but $\pi_{2}>\Gamma$, then $\hat{l}=\{1\}, \hat{m}=\{2\}, \hat{h}=\emptyset$, the platforms are $p^{A}=p^{B}=\pi_{2}$, and inequalities (14) and (15) are satisfied. Similarly, if $\pi_{2}>\pi_{1}>\frac{1}{2}$ but $\pi_{1}<1-\Gamma$, then $\hat{l}=\emptyset, \hat{m}=\{1\}, \hat{h}=\{2\}$, the platforms are $p^{A}=p^{B}=\pi_{1}$, and again (14) and (15) are satisfied. In these settings, the parties cater fully to the preferences of the less extreme group. Were one party to shift its platform in the direction of the more extreme group's ideal, it would capture that group's endorsement but lose the other's, as well as some votes among the outsiders. This deviation would not be profitable.

\section{Conclusions}

We have developed a model of political endorsements by special interest groups. In our model, the leader of a group endorses one party or another in a legislative election in order to communicate information about the group's interests to a set of like-minded but uninformed voters. The members use these cues to update their beliefs about what election outcomes might be good for them, and vote accordingly. In some cases, other voters-who do not share the same interests as the members-also learn from the endorsements and adjust their voting behavior as a result.

Parties will not always compete for interest groups' endorsements. In particular, endorsements are policy neutral when all voters hear them and voters who are not members of any group have interests that are diametrically opposed to those of members. In these circumstances, any concession that the parties might make to an interest group would cost them more votes among non-members than it would win them among the favored few. However, if the interests of group members are not perfectly complementary to those of outsiders, or if the endorsement by a group's leader is not readily observed by non-members, then parties indeed will find it worthwhile to compete for a group's backing. In such settings, the positions they take will favor the special interests at the expense of the unaffiliated voters.

Endorsements can enhance political efficiency by allowing the true interests of a set of otherwise uninformed voters to be reflected in the parties' platforms. But 
the competition for an interest group's backing may lead to over-representation of its members' interests, in which case the endorsement process might lower aggregate welfare. The competition for an endorsement is most intense - and the risk of inefficiency most severe--when the group is small and its members relatively centrist. In fact, a group whose members are truly moderates might fare better in an equilibrium with political endorsements than they would in one in which they were fully informed. This is due to the coarse nature of the endorsement "language". The endorsement provides listeners with a binary comparison, but does not reveal the intensity of the endorser's preference. Therefore, true moderates who hear their leader announcing his recommendation will not be able to rule out the possibility that they are really extreme. They will vote their expected interest, rather than their actual interest, and so the parties may cater to them more aggressively.

Our analysis has addressed the possibility that endorsements are issued according to simple rules and the possibility that they are designed strategically. We assumed that a mechanical endorser follows a dividing-line rule; i.e., he identifies a dividing line between the positions of the two parties, and endorses the party with the higher (lower) position if the members' true interests are above (below) the line. A strategic endorser must consider how his charges will interpret any pronouncements and optimize accordingly. But we found that a strategic endorser employs a particular dividing-line rule, so actually the two cases generate similar equilibria.

Finally, we studied situations where there is only one interest group and situations where many groups can issue endorsements. With one group, the parties need only consider that by pandering to the group's wishes they might alienate some of the unaffiliated voters. But with multiple groups, catering to one group can cost a party the endorsement of some others. In the equilibrium the parties locate toward the center of the pliable policy space, so that the endorsements they could win by shading their policy position further to one side just balance the endorsements they would lose from groups with opposing interests plus any loss of votes among unaffiliated voters. The equilibrium policy is displaced from the center in the direction favorable to the median interest-group member. 
Our model ascribes real effects to endorsements even though the parties' pliable platforms are the same in equilibrium and all equilibrium endorsements are random. These effects come from the competition for endorsements, not the endorsements themselves. In fact, even if endorsements never are issued, the mere fact that they might be can influence political outcomes! 
[11] Rapaport, Ronald B., Stone, Walter J. and Alan I. Abramowitz (1991), "Do Endorsements Matter: Group Influence in the 1984 Democratic Caucuses." American Political Science Review, 85, 193-203. 


\section{Appendix}

\section{Complete Statement and Proof of Proposition 3}

Let $\mu_{I}\left(\pi_{I} \mid p^{A}, p^{B}, E\right)$ be an insider's conditional probability distribution for $\pi_{I}$ when the platforms $p^{A}$ and $p^{B}$ and the endorsement $E$ is observed. The complete statement of Proposition 3 is as follows:

Proposition 3 Let the conditional distribution of $\pi$ for outsiders be independent of $\pi_{I}$ and let the endorsement be observable to all voters. Suppose that the endorsement obeys a dividing-line rule and that Assumptions 1 and 2 are satisfied. Then there exists a PBE in which

(i) $p^{A}\left(\pi_{I}\right)=p^{B}\left(\pi_{I}\right)=p\left(\pi_{I}\right)=\left\{\begin{array}{cc}\gamma & \text { for } 0 \leq \pi_{I} \leq \gamma ; \\ \pi_{I} & \text { for } \gamma<\pi_{I}<1-\gamma ; \\ 1-\gamma & \text { for } 1-\gamma \leq \pi_{I} \leq 1\end{array}\right.$

(ii) $q=1-\psi\left(\frac{1}{2}+b\right)$;

(iii) $\mathcal{E}_{O}\left(\pi \mid \Omega_{O}\right) \equiv \frac{1}{2}$

(iv) for all $\left(p^{A}, p^{B}\right)$ such that $p^{A} \neq p^{B}$ :

(a) $\mu_{I}\left(\pi_{I} \mid p^{A}, p^{B}, E_{\min }\left[p^{A}, p^{B}\right]\right)=f\left(\pi_{I}\right) / F\left[g\left(p^{A}, p^{B}\right)\right]$ for $\pi_{I} \in\left[0, g\left(p^{A}, p^{B}\right)\right]$ and zero otherwise;

(b) $\mu_{I}\left(\pi_{I} \mid p^{A}, p^{B}, E_{\max }\left[p^{A}, p^{B}\right]\right)=f\left(\pi_{I}\right) /\left\{1-F\left[g\left(p^{A}, p^{B}\right)\right]\right\}$ for $\pi_{I} \in\left[g\left(p^{A}, p^{B}\right), 1\right]$ and zero otherwise;

(v) for $p^{A}=p^{B} \in[0, \gamma) \cup(1-\gamma, 1]$ and $E=A$ or $E=B, \mu_{I}\left(\pi_{I} \mid p^{A}, p^{B}, E\right)=f\left(\pi_{I}\right)$ for $\pi_{I} \in[0,1]$

(vi) for $p^{A}=p^{B} \in(\gamma, 1-\gamma)$ and $E=A$ or $E=B, \mu_{I}\left(\pi_{I} \mid p^{A}, p^{B}, E\right)$ has a mass point of measure one at $\pi_{I}=p^{A}=p^{B}$;

(vii) for $p^{A}=p^{B}=\gamma$ and $E=A$ or $E=B, \mu_{I}\left(\pi_{I} \mid p^{A}, p^{B}, E\right)=f\left(\pi_{I}\right) / F(\gamma)$ for $\pi_{I} \in[0, \gamma]$ and zero otherwise;

(viii) for $p^{A}=p^{B}=1-\gamma$ and $E=A$ or $E=B, \mu_{I}\left(\pi_{I} \mid p^{A}, p^{B}, E\right)=f\left(\pi_{I}\right) /[1-F(\gamma)]$ for $\pi_{I} \in[1-\gamma, 1]$ and zero otherwise.

Proof: First observe that the updating of voters' beliefs is consistent with Bayes' rule. Outsiders learn nothing new from the announced policies and the group's endorsement about the locations of their ideal points. Part (iii) of the proposition ensures that their posterior beliefs are the same as their priors. If $p^{A} \neq p^{B}$, the endorsement tells insiders on which side of $g\left(p^{A}, p^{B}\right)$ the true $\pi_{I}$ lies. The updating specified in part (iv) is consistent with this new information. When $p^{A}=p^{B} \in(\gamma, 1-\gamma)$, insiders recognize that the announcements reveal the true value of $\pi_{I}$. Part (vi) of the proposition reflects this recognition. When $p^{A}=p^{B}=\gamma$, insiders realize that the true $\pi_{I}$ must be in $[0, \gamma]$. Part (vii) of the proposition is consistent with this. Similarly, when $p^{A}=p^{B}=1-\gamma, \pi_{I}$ must fall in the range $[1-\gamma, 1]$, and part (viii) reflects this. Finally, if $p^{A}=p^{B} \notin[\gamma, 1-\gamma]$, the endorsement tells the insiders nothing new. Part (v) specifies that the insiders do not update their priors in this case. 
Now consider the incentives facing the parties, when voters update according to (iii)-(viii). Take first the case in which $\pi_{I} \leq \gamma$. Suppose $p^{B}=\gamma$. If party $A$ sets $p^{A}=\gamma$, then equation (5) implies that $s=\frac{1}{2}+b$. If instead it sets $p^{A}>\gamma$, then $g\left(p^{A}, p^{B}\right)>\gamma \Rightarrow E=B$. Then part (iv) of the proposition implies that $\mathcal{E}_{I}\left[\pi_{I} \mid p^{A}, \gamma, B\right]=M\left[g\left(p^{A}, \gamma\right)\right]$, where $M(z)=\int_{0}^{z} x f(x) d x / F(z)$ (see (7)). Then part (iii) and equation (5) give

$$
s=\frac{1}{2}+b+2 k a T\left(s, p^{A}, \gamma\right)\left(\gamma-p^{A}\right),
$$

where $T\left(s, p^{A}, p^{B}\right) \equiv \psi(s) p^{A}+[1-\psi(s)] p^{B}-M\left[g\left(p^{A}, p^{B}\right)\right]-\frac{1-n}{2}$. The right-hand side of (A1) equals $\frac{1}{2}+b$ when $p^{A}=p^{B}=\gamma$, and is declining in $s$ for $p^{A} \neq p^{B}=\gamma$. So the $s$ that solves (A1) exceeds $\frac{1}{2}+b$ if and only if $T\left(\frac{1}{2}+b, p^{A}, \gamma\right)\left(\gamma-p^{A}\right)>0$. But note that

$$
\begin{aligned}
T\left(\frac{1}{2}+b, p^{A}, \gamma\right) & \geq \psi\left(\frac{1}{2}+b\right) g\left(p^{A}, \gamma\right)+\left[1-\psi\left(\frac{1}{2}+b\right)\right] \gamma-n M\left[g\left(p^{A}, \gamma\right)\right]-\frac{1-n}{2} \\
& \geq \psi\left(\frac{1}{2}+b\right) \gamma+\left[1-\psi\left(\frac{1}{2}+b\right)\right] \gamma-n M(\gamma)-\frac{1-n}{2} \\
& =0 .
\end{aligned}
$$

The first inequality follows from the fact that $p^{A}>\gamma$ and therefore $p^{A} \geq g\left(p^{A}, \gamma\right)$. The second inequality follows from Assumptions 1 and 2 and the fact that $p^{A}>\gamma \Rightarrow g\left(p^{A}, \gamma\right) \geq g(\gamma, \gamma)=\gamma$. Observe that the right-hand side of the first line is increasing in $p^{A}$ for $p^{A}>\gamma$ if and only if $\psi\left(\frac{1}{2}+b\right)-n M^{\prime}\left[g\left(p^{A}, \gamma\right)\right]>0$. However,

$$
\psi\left(\frac{1}{2}+b\right)-n M^{\prime}\left[g\left(p^{A}, \gamma\right)\right] \geq \psi\left(\frac{1}{2}+b\right)-n \mathcal{M} \geq 0
$$

by Assumption 2 (recall that $\mathcal{M}$ is the largest value of $M^{\prime}(\cdot)$ in the feasible range). Finally, the last equality in (A2) stems from the definition of $\gamma$ in (7). One of the inequalities must be strict, so $T\left(\frac{1}{2}+b, p^{A}, \gamma\right)>0$. Therefore, $s<\frac{1}{2}+b$ when $p^{A}>\gamma$.

The final option available to party $A$ is to set $p^{A}<\gamma$. Then $g\left(p^{A}, \gamma\right) \leq \gamma$. There are two subcases to consider. First, if $\pi_{I} \leq g\left(p^{A}, \gamma\right)$, then $E=A$ and part (iv) of the proposition implies $\mathcal{E}_{I}\left|\pi_{I}\right|$ $\left.p^{A}, \gamma, A\right]=M\left[g\left(p^{A}, \gamma\right)\right]$. Then (A1) gives the vote share for party $A$, and $s>\frac{1}{2}+b$ if and only if $T\left(\frac{1}{2}+b, p^{A}, \gamma\right)\left(\gamma-p^{A}\right)>0$. But now

$$
\begin{aligned}
T\left(\frac{1}{2}+b, p^{A}, \gamma\right) & \leq \psi\left(\frac{1}{2}+b\right) g\left(p^{A}, \gamma\right)+\left[1-\psi\left(\frac{1}{2}+b\right)\right] \gamma-n M\left[g\left(p^{A}, \gamma\right)\right]-\frac{1-n}{2} \\
& \leq \psi\left(\frac{1}{2}+b\right) \gamma+\left[1-\psi\left(\frac{1}{2}+b\right)\right] \gamma-n M(\gamma)-\frac{1-n}{2} \\
& =0
\end{aligned}
$$

by analogous arguments to those used above. Again, one of the inequalities must be strict, so $s<\frac{1}{2}+b$, since $\gamma>p^{A}$.

The second sub-case arises if $\pi_{I}>g\left(p^{A}, \gamma\right)$, in which case $E=B$. Then part (iv) of the proposition implies $\mathcal{E}_{I}\left[\pi \mid p^{A}, \gamma, B\right]=N\left[g\left(p^{A}, \gamma\right)\right]$, where $N(z)=\int_{z}^{1} x f(x) d x /[1-F(z)]$. The share of votes for party $A$ is given by

$$
s=\frac{1}{2}+b+2 k a Z\left(s, p^{A}, \gamma\right)\left(\gamma-p^{A}\right)
$$


where $Z\left(s, p^{A}, p^{B}\right) \equiv \psi(s) p^{A}+[1-\psi(s)] p^{B}-n N\left[g\left(p^{A}, p^{B}\right)\right]-\frac{1-n}{2}$. The right-hand side of (A3) equals $\frac{1}{2}+b$ when $p^{A}=p^{B}=\gamma$, and is declining in $s$ for $p^{A} \neq p^{B}=\gamma$. So the $s$ that solves (A3) exceeds $\frac{1}{2}+b$ if and only if $Z\left(\frac{1}{2}+b, p^{A}, \gamma\right)\left(\gamma-p^{A}\right)>0$; i.e., if and only if $Z\left(\frac{1}{2}+b, p^{A}, \gamma\right)>0$. But

$$
\begin{aligned}
Z\left(\frac{1}{2}+b, p^{A}, \gamma\right) & \leq \psi\left(\frac{1}{2}+b\right) g\left(p^{A}, \gamma\right)+\left[1-\psi\left(\frac{1}{2}+b\right)\right] \gamma-n N\left[g\left(p^{A}, \gamma\right)\right]-\frac{1-n}{2} \\
& \leq \psi\left(\frac{1}{2}+b\right) \gamma+\left[1-\psi\left(\frac{1}{2}+b\right)\right] \gamma-n N(\gamma)-\frac{1-n}{2} \\
& =0 .
\end{aligned}
$$

The first inequality follows from the fact that $p^{A}<p^{B}=\gamma$ and therefore $p^{A} \leq g\left(p^{A}, \gamma\right)$. The second inequality follows from Assumptions 1 and 2 and the fact that $p^{A}<\gamma \Rightarrow g\left(p^{A}, \gamma\right) \leq g(\gamma, \gamma)=$ $\gamma$. Observe that the right-hand side of the first line is increasing in $p^{A}$ for $p^{A}<\gamma$ if and only if $\psi\left(\frac{1}{2}+b\right)-n N^{\prime}\left[g\left(p^{A}, \gamma\right)\right]>0$. But from the definition of $N(\cdot)$ we have $N(z)=1-M(1-z)$ for all $z \in[0,1] . N(\cdot)$ is an increasing function and $N^{\prime}(z)=M^{\prime}(1-z)$. Therefore,

$$
\psi\left(\frac{1}{2}+b\right)-n N^{\prime}\left[g\left(p^{A}, \gamma\right)\right] \geq \psi\left(\frac{1}{2}+b\right)-n \mathcal{M} \geq 0,
$$

by Assumption 2. The equality in (A4) stems from the definition of $\gamma$. Again, at least one inequality in (A4) must be strict. We conclude that $s<\frac{1}{2}+b$ in this case as well.

It follows that $p^{A}=\gamma$ is a best response to $p^{B}=\gamma$ when $\pi_{I} \leq \gamma$. Similarly arguments can be use to establish that $p^{B}=\gamma$ is a best response to $p^{A}=\gamma$ for these values of $\pi_{I}$. Therefore, it is sequentially rational for the parties each to locate at $\gamma$ when $\pi_{I} \leq \gamma$.

An exactly analogous argument establishes that it is sequentially rational for the parties to each locate at $1-\gamma$ when $\pi_{I} \geq 1-\gamma$.

It remains to consider the case in which $\pi_{I} \in(\gamma, 1-\gamma)$. Suppose that $p^{B}=\pi_{I}$ and consider the incentives facing party $A$. If the party sets $p^{A}=\pi_{I}$, then $s=\frac{1}{2}+b$. If it sets $p^{A}>\pi_{I}$, then $p^{A} \geq$ $g\left(p^{A}, \pi_{I}\right) \geq \pi_{I}>\gamma$ and $E=B$. Part (iv) of the proposition implies $\mathcal{E}_{I}\left[\pi_{I} \mid p^{A}, \pi_{I}, B\right]=M\left[g\left(p^{A}, \pi_{I}\right)\right]$. Then part (iii) of the proposition and equation (5) imply

$$
s=\frac{1}{2}+b+2 k a T\left(s, p^{A}, \pi_{I}\right)\left(\pi_{I}-p^{A}\right) .
$$

In this case, $s>\frac{1}{2}+b$ if and only if $T\left(\frac{1}{2}+b, p^{A}, \pi_{I}\right)\left(\pi_{I}-p^{A}\right)>0$; i.e., if and only if $T\left(\frac{1}{2}+b, p^{A}, \pi_{I}\right)<0$. But

$$
\begin{aligned}
T\left(\frac{1}{2}+b, p^{A}, \pi_{I}\right) & \geq \psi\left(\frac{1}{2}+b\right) g\left(p^{A}, \pi_{I}\right)+\left[1-\psi\left(\frac{1}{2}+b\right)\right] \pi_{I}-n M\left[g\left(p^{A}, \pi_{I}\right)\right]-\frac{1-n}{2} \\
& \geq \psi\left(\frac{1}{2}+b\right) \gamma+\left[1-\psi\left(\frac{1}{2}+b\right)\right] \gamma-n M(\gamma)-\frac{1-n}{2} \\
& =0 .
\end{aligned}
$$

Therefore, $s<\frac{1}{2}+b$ when $p^{A}>\pi_{I}$, because one of the inequalities must be strict. 
The final option available to party $A$ is to set $p^{A}<\pi_{I}$. If it does so, then $p^{A} \leq g\left(p^{A}, \pi_{I}\right) \leq \pi_{I}<1-\gamma$ and $E=B$. Then

$$
s=\frac{1}{2}+b+2 k a Z\left(s, p^{A}, \pi_{I}\right)\left(\pi_{I}-p^{A}\right),
$$

and $s>\frac{1}{2}+b$ if and only if $Z\left(\frac{1}{2}+b, p^{A}, \pi_{I}\right)>0$. But

$$
\begin{aligned}
Z\left(\frac{1}{2}+b, p^{A}, \pi_{I}\right) & \leq \psi\left(\frac{1}{2}+b\right) g\left(p^{A}, \pi_{I}\right)+\left[1-\psi\left(\frac{1}{2}+b\right)\right] \pi_{I}-n N\left[g\left(p^{A}, \pi_{I}\right)\right]-\frac{1-n}{2} \\
& \leq \psi\left(\frac{1}{2}+b\right)(1-\gamma)+\left[1-\psi\left(\frac{1}{2}+b\right)\right](1-\gamma)-n N(1-\gamma)-\frac{1-n}{2} \\
& =0 .
\end{aligned}
$$

The last equality follows from (8) and the fact that $M(\gamma)+N(1-\gamma)=1$. Therefore, $s<\frac{1}{2}+b$ when $p^{A}<\pi_{I}$, because one of the inequalities must be strict.

It follows that $p^{A}=\pi_{I}$ is a best response to $p^{B}=\pi_{I}$ when $\pi_{I} \in(\gamma, 1-\gamma)$. Similar arguments can be used to establish that $p^{B}=\pi_{I}$ is a best response to $p^{A}=\pi_{I}$ for these values of $\pi_{I}$. Therefore, it is sequentially rational for the parties each to locate at $\pi_{I}$ when $\pi_{I} \in(\gamma, 1-\gamma)$.

\section{Proof of Proposition 5}

We proceed by construction. Suppose the members of the interest group suspect that their leader is using a dividing-line rule, with some particular function $g^{\circ}\left(p^{A}, p^{B}\right)$ giving the location of the dividing line. Suppose further that, upon hearing the policy stances and the leader's endorsement, these individuals update their beliefs about $\pi_{I}$ as specified in Proposition 3. This means that, if $p^{A} \neq p^{B}$ and $E=E_{\min }$, $\mathcal{E}_{I}\left[\pi_{I} \mid p^{A}, p^{B}, E_{\min }\right]=M\left[g^{\circ}\left(p^{A}, p^{B}\right)\right]$, while if $p^{A} \neq p^{B}$ and $E=E_{\max }, \mathcal{E}_{I}\left[\pi_{I} \mid p^{A}, p^{B}, E_{\max }\right]=$ $N\left[g^{\circ}\left(p^{A}, p^{B}\right)\right]$, where $N(z) \equiv \int_{z}^{1} x f(x) d x /[1-F(z)]$. Also, when outsiders hear different pliable platforms announced by the two parties, they believe their ideal point to be symmetrically distributed about one-half. Then, applying the voting rule in (4), we have

$$
s=\frac{1}{2}+b+2 k a\left\{p\left(s, p^{A}, p^{B}\right)-n \eta\left(p^{A}, p^{B}, E \mid g^{\circ}\right)-(1-n) \frac{1}{2}\right\}\left(p^{B}-p^{A}\right)
$$

where $p\left(s, p^{A}, p^{B}\right) \equiv \psi(s) p^{A}+[1-\psi(s)] p^{B}$ and

$$
\eta\left(p^{A}, p^{B}, E \mid g^{\circ}\right) \equiv\left\{\begin{array}{lr}
M\left[g^{\circ}\left(p^{A}, p^{B}\right)\right] & \text { for } E=E_{\min } \\
N\left[g^{\circ}\left(p^{A}, p^{B}\right)\right] & \text { for } E=E_{\max }
\end{array}\right.
$$

Equation (A5) defines an implicit mapping from the parties' platforms and the identity of the endorsee to the implied vote share for party $A$. This mapping depends on what dividing line $g^{\circ}\left(p^{A}, p^{B}\right)$ the members suspect their leader of using. We denote the mapping by $\tilde{s}\left(p^{A}, p^{B}, E \mid g^{\circ}\right)$.

The properties of $\tilde{s}\left(p^{A}, p^{B}, E \mid g^{\circ}\right)$ can be understood with the aid of Figure 3. First note that $\tilde{s}\left(p^{A}, p^{B}, E \mid g^{\circ}\right)=\frac{1}{2}+b$ for all $p^{A}=p^{B}$, independent of $g^{\circ}$. The curve $S S$ in Figure 3 depicts the qualitative properties of the right-hand side of (A5) for any pair of platforms that are not the same. 
This curve always slopes downward, as shown. Where it intersects the $45^{\circ}$ line, we have the (unique) value of $\tilde{s}$. We know, moreover, that given the parties' positions $p^{A}$ and $p^{B}$, the right-hand side of (A5) is larger for $E=A$ than it is for $E=B$. This ensures that, by endorsing a particular party, the group leader always furthers that party's electoral cause.

Once we know how the composition of the legislature responds to the platforms and the endorsement (given the dividing-line rule), we can compute how the pliable policy outcome responds to these variables as well. We define

$$
\tilde{p}\left(p^{A}, p^{B}, E \mid g^{\circ}\right) \equiv \psi\left[\tilde{s}\left(p^{A}, p^{B}, E \mid g^{\circ}\right)\right] p^{A}+\left\{1-\psi\left[\tilde{s}\left(p^{A}, p^{B}, E \mid g^{\circ}\right)\right]\right\} p^{B}
$$

as the anticipated pliable compromise when the platforms are $p^{A}$ and $p^{B}$, the leader endorses $E$, and the insiders use the dividing-line $g^{\circ}\left(p^{A}, p^{B}\right)$ in updating their beliefs. The properties of $\tilde{s}(\cdot)$ imply that $\tilde{p}\left(p^{A}, p^{B}, E_{\max } \mid g^{\circ}\right)>\tilde{p}\left(p^{A}, p^{B}, E_{\min } \mid g^{\circ}\right)$.

We are now ready to describe the optimal endorsement rule for the interest-group leader to follow. The leader uses the function $\tilde{p}(\cdot)$ to evaluate the consequences of his endorsement options. He then issues the endorsement that minimizes the distance of the compromise pliable policy from the target $\pi_{I}$. If these distances happen to be the same, he endorses each party with probability one-half. Then the strategic endorsement rule is itself a dividing-line rule, with

$$
\tilde{g}\left(p^{A}, p^{B} \mid g^{\circ}\right) \equiv \frac{1}{2}\left[\tilde{p}\left(p^{A}, p^{B}, A \mid g^{\circ}\right)+\tilde{p}\left(p^{A}, p^{B}, B \mid g^{\circ}\right)\right] .
$$

In particular, note that $\tilde{g}(\cdot)$ is continuous, because $\tilde{p}(\cdot)$ is continuous, and that $\tilde{g}(\cdot)$ falls between $\min \left\{p^{A}, p^{B}\right\}$ and $\max \left\{p^{A}, p^{B}\right\}$, because $\tilde{p}(\cdot)$ does. Equation (A6) provides a mapping from $g^{\circ}$ to $\tilde{g}$. We wish to establish that this mapping has a fixed point.

To find the fixed point in the mapping from $g^{\circ}$ to $\tilde{g}$, observe that (A5) implies a link between the expected value of $\pi_{I}, \pi_{I}^{e}=\mathcal{E}_{I}\left[\pi_{I} \mid \Omega_{I}\right]$, and the pliable policy $p$, which is implicitly defined by the following two equations:

$$
\begin{gathered}
s=\frac{1}{2}+b+2 k a\left[p-n \pi_{I}^{e}-(1-n) \frac{1}{2}\right]\left(p^{B}-p^{A}\right) \\
p=\psi(s) p^{A}+[1-\psi(s)] p^{B} .
\end{gathered}
$$

$>$ From these equations we can solve both $s$ and $p$ as functions of $p^{A}, p^{B}$ and $\pi_{I}^{e}$. Denote the solution for $p$ by $\hat{p}\left(p^{A}, p^{B}, \pi_{I}^{e}\right)$. Clearly, $\hat{p}(\cdot)$ lies between $p^{A}$ and $p^{B}$ and it is increasing in $\pi_{I}^{e}$ for $p^{A} \neq p^{B}$. Moreover, by Assumption 2

$$
0<\frac{\partial \hat{p}(\cdot)}{\partial \pi_{I}^{e}}=\frac{2 k a \psi^{\prime}(\cdot)\left(p^{B}-p^{A}\right)^{2} n}{1+2 k a \psi^{\prime}(\cdot)\left(p^{B}-p^{A}\right)^{2}}<1 \text { for all } p^{A} \neq p^{B} \text { and } p^{A}, p^{B}, \pi_{I}^{e} \in[0,1] .
$$

In addition, it follows from (A5) that

$$
\tilde{p}\left(p^{A}, p^{B}, A \mid g^{\circ}\right)+\tilde{p}\left(p^{A}, p^{B}, B \mid g^{\circ}\right) \equiv \hat{p}\left(p^{A}, p^{B}, M\left[g^{\circ}\left(p^{A}, p^{B}\right)\right]\right)+\hat{p}\left(p^{A}, p^{B}, N\left[g^{\circ}\left(p^{A}, p^{B}\right)\right]\right)
$$


Using this relationship, we can rewrite (A6) as

$$
\tilde{g}\left(p^{A}, p^{B} \mid g^{\circ}\right) \equiv \frac{1}{2}\left\{\hat{p}\left(p^{A}, p^{B}, M\left[g^{\circ}\left(p^{A}, p^{B}\right)\right]\right)+\hat{p}\left(p^{A}, p^{B}, N\left[g^{\circ}\left(p^{A}, p^{B}\right)\right]\right)\right\} .
$$

This is an alternative representation of the mapping from $g^{\circ}$ to $\tilde{g}$ for which we seek a fixed point. If such a fixed point $g$ exists, it is defined by $\hat{g}=g\left(p^{A}, p^{B}\right)$ for all $p^{A}, p^{B} \in[0,1]$, where $\hat{g}$ solves

$$
\hat{g}=\Phi\left(p^{A}, p^{B}, \hat{g}\right)
$$

and

$$
\Phi\left(p^{A}, p^{B}, \hat{g}\right) \equiv \frac{1}{2}\left\{\hat{p}\left[p^{A}, p^{B}, M(\hat{g})\right]+\hat{p}\left[p^{A}, p^{B}, N(\hat{g})\right]\right\} .
$$

The only question that remains to be settled is whether there exists a solution $\hat{g}$ for every feasible pair of pliable policies. If a solution exists for every $p^{A}, p^{B} \in[0,1]$, then $g$ is a fixed point of the mapping in (A6). We now show that a solution exists.

First observe that for $p^{A}=p^{B}$ we have $\hat{p}\left[p^{A}, p^{B}, M(\hat{g})\right]=p^{A}=p^{B}$ for all $\hat{g} \in[0,1]$. Therefore, in these cases, the unique $\hat{g}$ that solves (A8) is $\hat{g}=p^{A}=p^{B}$. Next suppose that $p^{A} \neq p^{B}$. In the event, $\Phi\left(p^{A}, p^{B}, \hat{g}\right)$ is increasing in $\hat{g}$, because both $M(\cdot)$ and $N(\cdot)$ are increasing functions (see (A7)). But $\min \left\{p^{A}, p^{B}\right\} \leq \Phi\left(p^{A}, p^{B}, \min \left\{p^{A}, p^{B}\right\}\right)$ and $\Phi\left(p^{A}, p^{B}, \max \left\{p^{A}, p^{B}\right\}\right) \leq \max \left\{p^{A}, p^{B}\right\}$, because $\hat{p}(\cdot)$ is between $p^{A}$ and $p^{B}$. Therefore (A8) has a solution $\hat{g}, \min \left\{p^{A}, p^{B}\right\} \leq \hat{g} \leq \max \left\{p^{A}, p^{B}\right\}$. It follows that the mapping in (A6) has a fixed point.

\section{Proof of Proposition 6}

We define $\pi \equiv\left(\pi_{1}, \pi_{2}, \ldots, \pi_{S}\right), \pi_{\max } \equiv \max _{i}\left\{\pi_{1}, \pi_{2}, \ldots, \pi_{S}\right\}$ and $\pi_{\min } \equiv \min _{i}\left\{\pi_{1}, \pi_{2}, \ldots, \pi_{S}\right\}$. Let $l\left(p^{A}, p^{B} \mid \pi\right) \equiv\left\{i \mid \pi_{i}<g_{i}\left(p^{A}, p^{B}\right)\right\} ;$ i.e., $l(\cdot)$ is the set of interest groups that have median ideal points below their dividing lines when the parties have announced pliable platforms of $p^{A}$ and $p^{B}$. Similarly, $m\left(p^{A}, p^{B} \mid \pi\right) \equiv\left\{i \mid \pi_{i}=g_{i}\left(p^{A}, p^{B}\right)\right\}$ and $h\left(p^{A}, p^{B} \mid \pi\right) \equiv\left\{i \mid \pi_{i}>g_{i}\left(p^{A}, p^{B}\right)\right\}$. Then, assuming the various insiders update their beliefs as described in (iv)-(viii) of Proposition 3 in the appendix, the voting rule (4) implies

where $e^{16}$

$$
s=\frac{1}{2}+b+2 a k X\left(s, p^{A}, p^{B} \mid \pi\right)\left(p^{B}-p^{A}\right)
$$

$$
\begin{aligned}
X\left(s, p^{A}, p^{B} \mid \pi\right) \equiv & \psi(s) p^{A}+[1-\psi(s)] p^{B} \\
& -\sum_{i \in l\left(p^{A}, p^{B} \mid \pi\right)} n_{i} M_{i}\left[g_{i}\left(p^{A}, p^{B}\right)\right] \\
& -\sum_{i \in m\left(p^{A}, p^{B} \mid \pi\right)} \frac{n_{i}}{2}\left\{M_{i}\left[g_{i}\left(p^{A}, p^{B}\right)\right]+N_{i}\left[g_{i}\left(p^{A}, p^{B}\right)\right]\right\}
\end{aligned}
$$

\footnotetext{
${ }^{16}$ The third line in the following equations takes account of the fact that when $\pi_{i}=g_{i}\left(p^{A}, p^{B}\right)$ the leader of interest group $i$ endorses each party with equal probability.
} 


$$
-\sum_{i \in h\left(p^{A}, p^{B} \mid \pi\right)} n_{i} N_{i}\left[g_{i}\left(p^{A}, p^{B}\right)\right]-\frac{1}{2}\left(1-\sum_{i \in S} n_{i}\right) .
$$

Since the function $X(\cdot)$ is increasing in $s$ for $p^{A}>p^{B}$ and is decreasing in $s$ for $p^{A}<p^{B}$, it follows from the parties' strategic behavior that $p^{A}=p^{B}=\hat{p}$ is an equilibrium if and only if

(i) $X\left(\frac{1}{2}+b, p^{A}, \hat{p} \mid \pi\right) \geq 0$ for all $p^{A}>\hat{p}$;

(ii) $X\left(\frac{1}{2}+b, p^{A}, \hat{p} \mid \pi\right) \leq 0$ for all $p^{A}<\hat{p}$;

(iii) $X\left(\frac{1}{2}+b, \hat{p}, p^{B} \mid \pi\right) \leq 0$ for all $p^{B}<\hat{p}$;

(iv) $X\left(\frac{1}{2}+b, \hat{p}, p^{B} \mid \pi\right) \geq 0$ for all $p^{B}>\hat{p}$.

Let $\hat{l} \equiv l(\hat{p}, \hat{p} \mid \pi), \hat{m} \equiv m(\hat{p}, \hat{p} \mid \pi)$, and $\hat{h} \equiv h(\hat{p}, \hat{p} \mid \pi)$; these are the sets of interest groups with median ideal points below, equal to, and above the pliable policy in equilibrium. The requirements for a Nash equilibrium (i)-(iv) imply that $X\left(\frac{1}{2}+b, \hat{p}, \hat{p} \mid \pi\right)=0$ when $\hat{m}$ is empty and that $\hat{p}_{j}=\pi_{j}$ for all $j$ in $\hat{m}$, when $\hat{m}$ is non-empty. ${ }^{17}$

Now define $\Gamma$ as the parameter that solves

$$
\Gamma=\sum_{i \in S} n_{i} M_{i}(\Gamma)+\left(1-\sum_{i \in S} n_{i}\right) \frac{1}{2}
$$

This equation has a solution $0<\Gamma<1 / 2$ because the right-hand side is continuous, increasing in $\Gamma$, is larger than zero for $\Gamma=0$, and is smaller than $1 / 2$ for $\Gamma=1 / 2$.

Next observe that

$$
\begin{aligned}
Y(p \quad \mid \quad \pi) & \equiv 2 X(s, p, p \mid \pi)= \\
& 2 p-2 \sum_{i \in l(p, p \mid \pi)} n_{i} M_{i}(p)-\sum_{i \in m(p, p \mid \pi)} n_{i}\left[M_{i}(p)+N_{i}(p)\right] \\
& -2 \sum_{i \in h(p, p \mid \pi)} n_{i} N_{i}(p)-1+\sum_{i \in S} n_{i} .
\end{aligned}
$$

The function $Y(p \mid \pi)$ is increasing in $p$ due to Assuption 3, and continuous whenever $m(p, p \mid \pi)=\varnothing . .^{18}$ Therefore:

\footnotetext{
${ }^{17}$ Note that $X\left(s, p^{A}, p^{B} \mid \pi\right)$ is continuous in $p^{A}$ and $p^{B}$ whenever $m\left(p^{A}, p^{B} \mid \pi\right)=\emptyset$, which implies the first part of the statement. The second part follows immediately from the definition of $\hat{m}$.

${ }^{18}$ Note that

$$
Y\left(\pi_{i} \mid \pi\right)-Y\left(\pi_{i}^{-} \mid \pi\right)=Y\left(\pi_{i}^{+} \mid \pi\right)-Y\left(\pi_{i} \mid \pi\right)=\sum_{j \in m\left(\pi_{i}, \pi_{i} \mid \pi\right)} n_{j}\left[N_{j}(p)-M_{j}(p)\right] \text { for all } i \in N
$$

Therefore $Y(\cdot)$ is not continuous at $p=\pi_{i}$
} 
1. For $p<\min \left\{\pi_{\min }, 1-\Gamma\right\}$,

$$
\begin{aligned}
Y(p \quad \mid \quad \pi)=2 p-2 \sum_{i \in S} n_{i} N_{i}(p)-1+\sum_{i \in S} n_{i} \\
<2(1-\Gamma)-2 \sum_{i \in S} n_{i} N_{i}(1-\Gamma)-1+\sum_{i \in S} n_{i} \\
\quad=2\left[1-\sum_{i \in S} n_{i} M_{i}(\Gamma)-\frac{1}{2}\left(1-\sum_{i \in S} n_{i}\right)\right]-2 \sum_{i \in S} n_{i} N_{i}(1-\Gamma)-1+\sum_{i \in S} n_{i}=0
\end{aligned}
$$

The inequality follows from the fact that $Y(\cdot)$ is increasing in $p$. The subsequent equality follows from (A7) and the final equality follows the fact that $M_{i}(p)+N_{i}(p)=1$ for all feasible policies.

2. For $p>\max \left\{\pi_{\max }, \Gamma\right\}$,

$$
\begin{aligned}
Y(p \quad \mid \pi)=2 p-2 \sum_{i \in S} n_{i} M_{i}(p)-1+\sum_{i \in S} n_{i} \\
>\quad 2 \Gamma-2 \sum_{i \in S} n_{i} M_{i}(\Gamma)-1+\sum_{i \in S} n_{i}=0 .
\end{aligned}
$$

Again, the first inequality follows from the fact that $Y(\cdot)$ is an increasing function and the last equality follows from (A7).

Therefore, either ${ }^{19}$

(a) there exists a unique $\hat{p} \in\left[\min \left\{\pi_{\min }, 1-\Gamma\right\}, \max \left\{\pi_{\max }, \Gamma\right\}\right]$ such that $Y(\hat{p} \mid \pi)=0$ and $\hat{m}=\varnothing$; or

(b) there exists a unique non-empty set $\hat{m}$ such that $Y\left(\hat{p}^{-} \mid \pi\right) \leq 0 \leq Y\left(\hat{p}^{+} \mid \pi\right)$.

It follows from the definition of $Y$ that when (a) applies,

$$
\hat{p}=\sum_{i \in \hat{l}} n_{i} M_{i}(\hat{p})+\sum_{i \in \hat{h}} n_{i} N_{i}(\hat{p})+\frac{1}{2}\left(1-\sum_{i \in S} n_{i}\right),
$$

whereas when (b) applies

$$
\hat{p} \geq \sum_{i \in \hat{l} \cup \hat{m}} n_{i} M_{i}(\hat{p})+\sum_{i \in \hat{h}} n_{i} N_{i}(\hat{p})+\frac{1}{2}\left(1-\sum_{i \in S} n_{i}\right)
$$

and

$$
\hat{p} \leq \sum_{i \in \hat{l}} n_{i} M_{i}(\hat{p})+\sum_{i \in \hat{h} \cup \hat{m}} n_{i} N_{i}(\hat{p})+\frac{1}{2}\left(1-\sum_{i \in S} n_{i}\right) .
$$

These are the conditions specified in Proposition 6. We now proceed to prove that a $\hat{p}$ satisfying (a) or (b) is an equilibrium; i.e., that neither party has an incentive to deviate when it anticipates that the other will announce a platform of $\hat{p}$.

\footnotetext{
${ }^{19}$ Conditions (a) and (b) cannot hold simultaneously. Each condition implies $\Gamma \leq \hat{p} \leq 1-\Gamma$. Moreover, when $\pi_{\max } \leq \Gamma$, $\hat{p}=\Gamma$ and when $\pi_{\min } \geq 1-\Gamma, \hat{p}=1-\Gamma$, just as in the single-group case.
} 
We begin with the extreme case in which $\pi_{\max }<\Gamma$. Then (a) applies and $\hat{p}=\Gamma$. Consider the incentives facing party $A$. If it announces a $p^{A}>\Gamma$ then

$$
\begin{aligned}
X\left(\frac{1}{2}+b, p^{A}, \Gamma \mid \pi\right) \geq & \psi\left(\frac{1}{2}+b\right) \frac{1}{\sum_{i \in S} n_{i}} \sum_{i \in S} g_{i}\left(p^{A}, \Gamma\right)+\left[1-\psi\left(\frac{1}{2}+b\right)\right] \Gamma \\
& -\sum_{i \in S} n_{i} M_{i}\left[g_{i}\left(p^{A}, \Gamma\right)\right]-\frac{1}{2}\left(1-\sum_{i \in S} n_{i}\right) \\
\geq & \Gamma-\sum_{i \in S} n_{i} M_{i}(\Gamma)-\frac{1}{2}\left(1-\sum_{i \in S} n_{i}\right)=0 .
\end{aligned}
$$

The first inequality follows from the fact that $g_{i}\left(p^{A}, \Gamma\right) \leq p^{A}$ for all $i$. The second inequality follows from Assumption 3 and the fact that $\Gamma \leq g_{i}\left(p^{A}, \Gamma\right)$ for all $i$. Therefore the equilibrium condition (i) is satisfied.

Now suppose party $A$ were to announce a platform of $p^{A}<\Gamma$. This may lead some interest groups to shift from set $\hat{l}$ to either $m\left(p^{A}, \Gamma \mid \pi\right)$ or $h\left(p^{A}, \Gamma \mid \pi\right)$. Observe, however, that each such shift reduces the value of $X\left(\frac{1}{2}+b, p^{A}, \Gamma \mid \pi\right)$. Therefore

$$
\begin{aligned}
X\left(\frac{1}{2}+b, p^{A}, \Gamma \mid \pi\right) \leq & \psi\left(\frac{1}{2}+b\right) p^{A}+\left[1-\psi\left(\frac{1}{2}+b\right)\right] \Gamma \\
& -\sum_{i \in S} n_{i} M_{i}\left[g_{i}\left(p^{A}, \Gamma\right)\right]-\frac{1}{2}\left(1-\sum_{i \in S} n_{i}\right) .
\end{aligned}
$$

$>$ From this inequality it also follows, by arguments similar to those above, that

$$
\begin{aligned}
X\left(\frac{1}{2}+b, p^{A}, \Gamma \mid \pi\right) \leq & \psi\left(\frac{1}{2}+b\right) \frac{1}{\sum_{i \in S} n_{i}} \sum_{i \in S} g_{i}\left(p^{A}, \Gamma\right)+\left[1-\psi\left(\frac{1}{2}+b\right)\right] \Gamma \\
& -\sum_{i \in S} n_{i} M_{i}\left[g_{i}\left(p^{A}, \Gamma\right)\right]-\frac{1}{2}\left(1-\sum_{i \in S} n_{i}\right) \\
\leq & \Gamma-\sum_{i \in S} n_{i} M_{i}(\Gamma)-\frac{1}{2}\left(1-\sum_{i \in S} n_{i}\right)=0 .
\end{aligned}
$$

Thus, equilibrium condition (ii) is satisfied.

Conditions (iii) and (iv) are used in the same way to show that party $B$ has also no incentive to deviate under these circumstances.

For the other extreme case, $\pi_{\min }>1-\Gamma$, it can be shown similarly that $\hat{p}=1-\Gamma$ satisfies conditions (i)-(iv).

The remaining cases arise when $\pi_{\max }>\Gamma$ and $\pi_{\min }<1-\Gamma$. Suppose then that there exists a $\hat{p}$ satisfying (a) or (b) and consider a deviation by party $A$ to $p^{A}>\hat{p}$. In this situation, the definition of $X$ implies

$$
X\left(\frac{1}{2}+b, p^{A}, \hat{p} \mid \pi\right)=\psi\left(\frac{1}{2}+b\right) p^{A}+\left[1-\psi\left(\frac{1}{2}+b\right)\right] \hat{p}
$$




$$
\begin{aligned}
& -\sum_{i \in l\left(p^{A}, \hat{p} \mid \pi\right)} n_{i} M_{i}\left[g_{i}\left(p^{A}, \hat{p}\right)\right] \\
& -\sum_{i \in m\left(p^{A}, \hat{p} \mid \pi\right)} \frac{n_{i}}{2}\left\{M_{i}\left[g_{i}\left(p^{A}, \hat{p}\right)\right]+N_{i}\left[g_{i}\left(p^{A}, \hat{p}\right)\right]\right\} \\
& -\sum_{i \in h\left(p^{A}, \hat{p} \mid \pi\right)} n_{i} N_{i}\left[g_{i}\left(p^{A}, \hat{p}\right)\right]-\frac{1}{2}\left(1-\sum_{i \in S} n_{i}\right) .
\end{aligned}
$$

The right-hand side of this expression is increasing in $p^{A}$ when the sets $l\left(p^{A}, \hat{p} \mid \pi\right), m\left(p^{A}, \hat{p} \mid \pi\right)$ and $h\left(p^{A}, \hat{p} \mid \pi\right)$ are held constant (due to Assumption 3). Moreover, because by raising $p^{A}$ either $m\left(p^{A}, \hat{p} \mid \pi\right)=\hat{m}$, or some groups shift from $\hat{m}$ to $l\left(p^{A}, \hat{p} \mid \pi\right)$ while some others shift from $h(\hat{p}, \hat{p} \mid \pi)$ to either $m\left(p^{A}, \hat{p} \mid \pi\right)$ or to $l\left(p^{A}, \hat{p} \mid \pi\right)$ and each such shift raises the right-hand side, the right-hand side is increasing in $p^{A}$ when these sets are also adjusted.

Now consider the limiting value of the right-hand side when $p^{A} \rightarrow \hat{p}$ from above. Clearly, as $A$ 's policy declines the right-hand side declines. If case (a) applies then $m\left(p^{A}, \hat{p} \mid \pi\right) \rightarrow \hat{m}=\varnothing$ and we obtain

$$
X\left(\frac{1}{2}+b, p^{A}, \hat{p} \mid \pi\right) \geq \hat{p}-\sum_{i \in \hat{l}} n_{i} M_{i}(\hat{p})-\sum_{i \in \hat{h}} n_{i} N_{i}(\hat{p})-\frac{1}{2}\left(1-\sum_{i \in S} n_{i}\right)=0,
$$

which satisfies condition (i) (the last equality follows from (15)). If case (b) applies, the limit of the right-hand side of (A8) implies

$$
X\left(\frac{1}{2}+b, p^{A}, \hat{p} \mid \pi\right) \geq \hat{p}-\sum_{i \in \hat{l} \cup \hat{m}} n_{i} M_{i}(\hat{p})-\sum_{i \in \hat{h}} n_{i} N_{i}(\hat{p})-\frac{1}{2}\left(1-\sum_{i \in S} n_{i}\right) \geq 0,
$$

which also satisfies condition (i) (the last inequality follows from (16)).

Next consider a deviation to $p^{A}<\hat{p}$ by party $A$. In this case too (A8) applies and its righthand side is increasing in $p^{A}$. Now consider the limiting value of the right-hand side when $p^{A} \rightarrow \hat{p}$ from below. Clearly, as $A$ 's policy rises the right-hand side of (A8) increases. If case (a) applies then $m\left(p^{A}, \hat{p} \mid \pi\right) \rightarrow \hat{m}=\varnothing$ and we obtain

$$
X\left(\frac{1}{2}+b, p^{A}, \hat{p} \mid \pi\right) \leq \hat{p}-\sum_{i \in \hat{l}} n_{i} M_{i}(\hat{p})-\sum_{i \in \hat{h}} n_{i} N_{i}(\hat{p})-\frac{1}{2}\left(1-\sum_{i \in S} n_{i}\right)=0,
$$

which satisfies condition (ii) (the last equality follows from (15)). Or case (b) applies. In this event the limit of the right-hand side of (A8) implies

$$
X\left(\frac{1}{2}+b, p^{A}, \hat{p} \mid \pi\right) \leq \hat{p}-\sum_{i \in \hat{l}} n_{i} M_{i}(\hat{p})-\sum_{i \in \hat{h} \cup \hat{m}} n_{i} N_{i}(\hat{p})-\frac{1}{2}\left(1-\sum_{i \in S} n_{i}\right) \leq 0,
$$

which also satisfies condition (ii) (the last inequality follows from (17)).

Using conditions (iii) and (iv) similar arguments establish that it does not pay party $B$ to deviate. This completes the proof of the proposition. 


\title{
Figure 1 \\ Information from Endorsement
}

\author{
Dividing Line
}

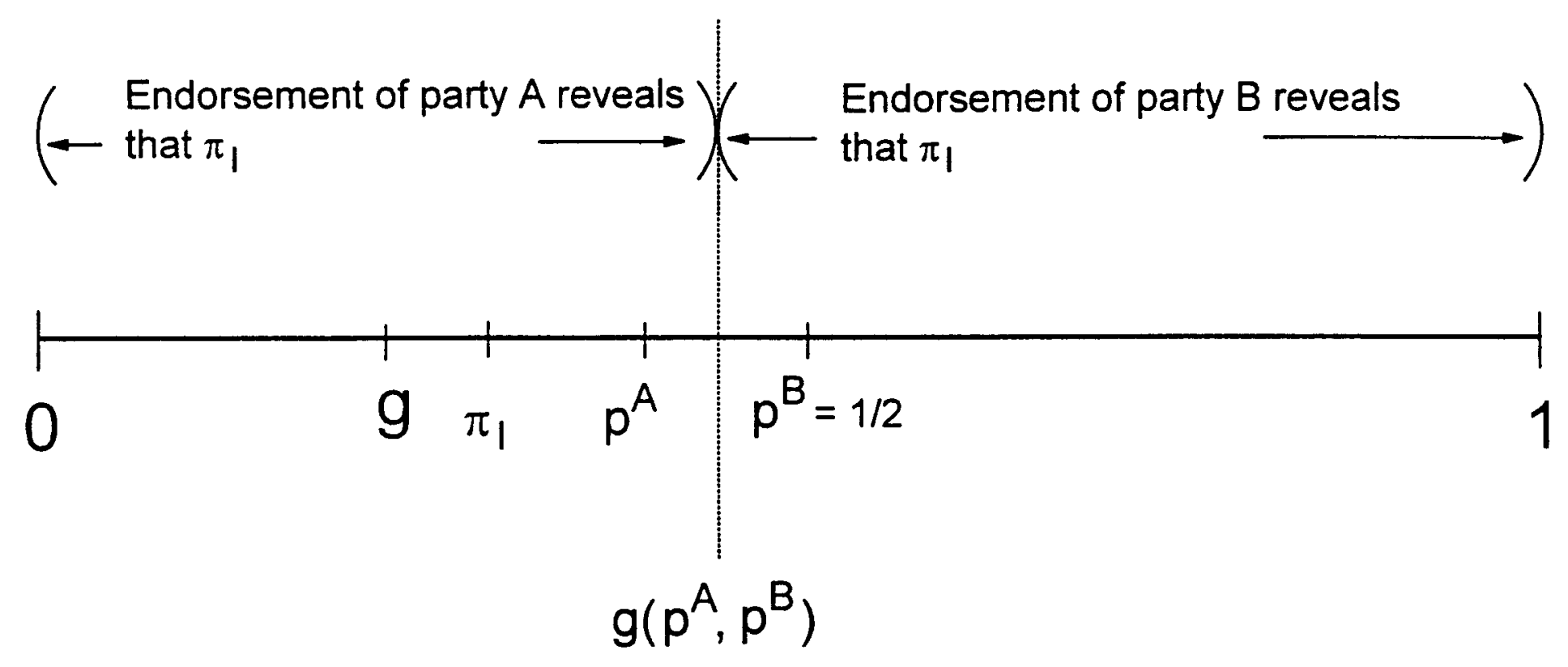




\section{Figure 2 \\ Vote Counts}

votes for $\mathrm{A}$

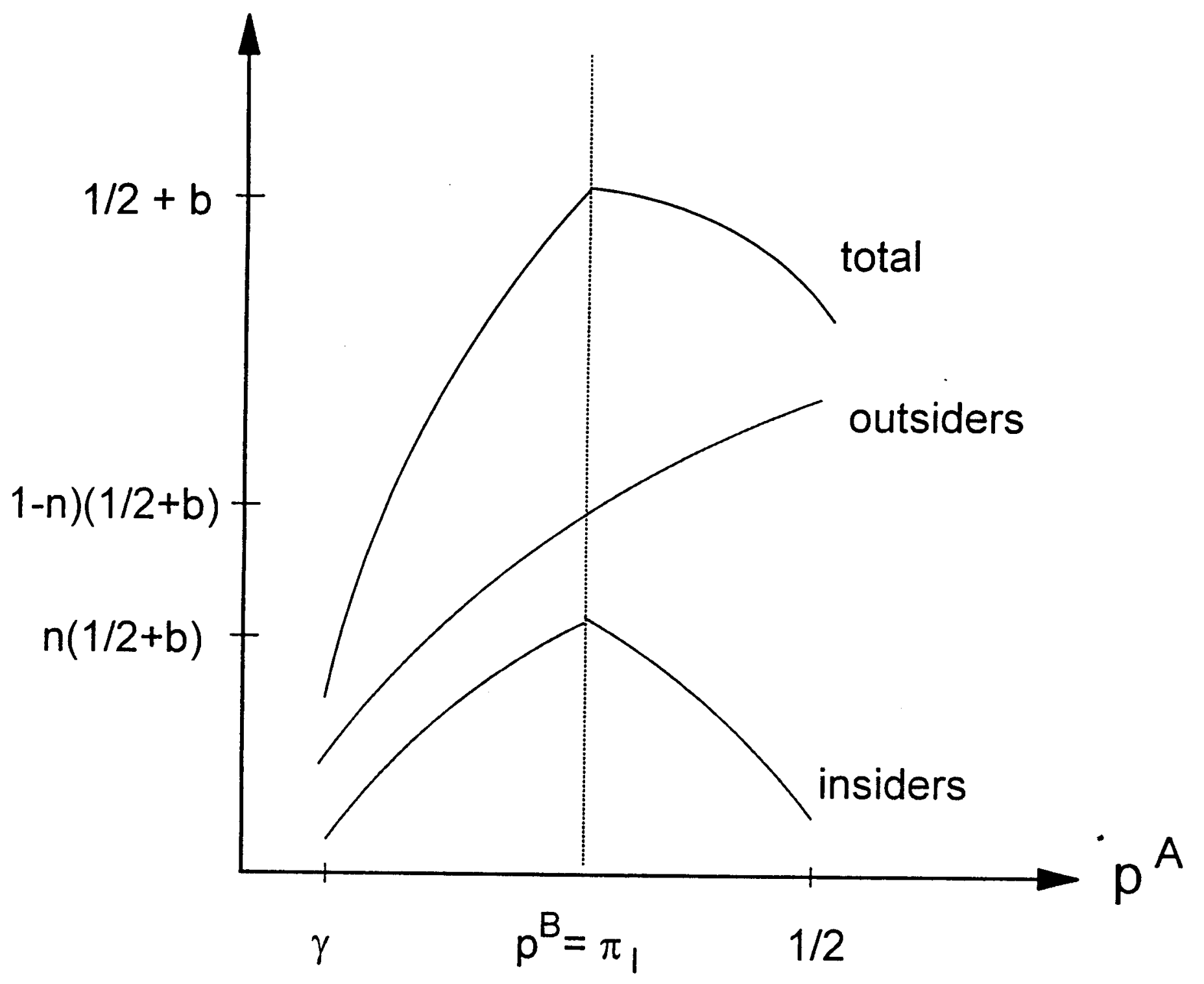


Figure 3

Equilibrium Vote Shares

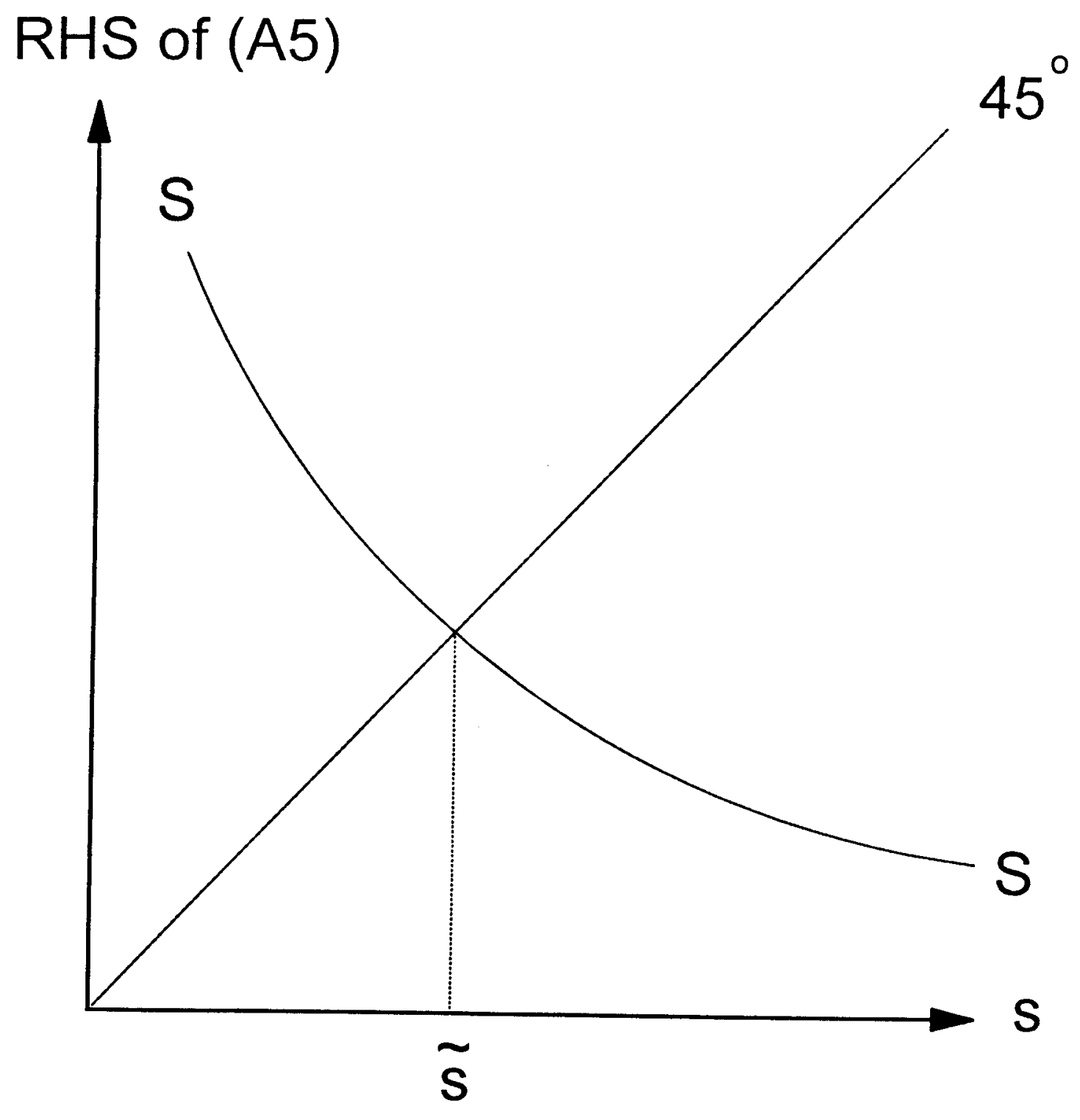




\title{
THE FOERDER INSTITUTE FOR ECONOMIC RESEARCH and THE SACKLER INSTITUTE FOR ECONOMIC STUDIES
}

\section{The Eitan Berglas School of Economics \\ Tel-Aviv University \\ List of Recent Working Papers}

\author{
41-96 \\ Dan Ben-David \\ (Foerder) \\ David H.Papell \\ 42-96 \\ Momi Dahan \\ (Sackler) \\ Daniel Tsiddon \\ 43-96 \\ Chaim Fershtman \\ (Foerder) \\ Uri Gneezy \\ 44-96 \\ (Foerder) \\ Todd R.Kaplan \\ David Wettstein \\ 45-96 \\ (Sackler) \\ Bhaskar Chakravorti \\ Yossef Spiegel \\ 1-97 \\ (Foerder) \\ Michael Kaganovic \\ Itzhak Zilcha \\ 2-97 \\ (Foerder) \\ David Pines \\ 3-97 \\ (Sackler) \\ Dan Ben-David \\ 4-97 \\ (Foerder) \\ Martin J. Osborne \\ 5-97 \\ (Foerder) \\ Itzhak Zilcha \\ 6-97 \\ (Sackler) \\ Robert M.Sauer \\ 7-97 \\ Krzysztof Burdzy \\ (Foerder) \\ David M.Frankel \\ Ady Pauzner
8-97 Krzysztof Burdzy
(Foerder) David M.Frankel
Ady Pauzner \\ 9-97 \\ (Sackler) \\ Zvi Hercowitz \\ Structural Change and International Trade \\ Demographic Transition, Income Distribution, and Economic \\ Growth \\ Strategic Delegation: An Experiment \\ Cost Sharing: Efficiency and Implementation \\ A Posnerian Model of Entry into Regulated Markets \\ Education, Social Security and Growth \\ Specialization and Trade: The Perspective of Club \\ and Local Public Good Theories \\ Knowledge Dissemination, Capital Accumulation, Trade, \\ and Endogenous Growth \\ Games with Procedurally Rational Players \\ Firms Under Tax Asymmetry: Price Uncertainty and \\ Hedging \\ Educational Debt, Loan-Forgiveness and Adverse \\ Selection in the Market for Lawyers \\ Fast Equilibrium Selection by Rational Players Living \\ in a Changing World \\ On the Time and Direction of Stochastic Bifurcation
}

Coples of the working papers or a complete working paper list of the two Institutes can be obtained from: Mrs.Stella Padeh, The Foerder Institute for Economic Research, Tel-Aviv University, Tel-Aviv, 69978 Israel.

Fax: 972-3-640-9908. e-mail: foerder@econ.tau.ac.il

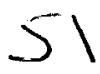




\begin{tabular}{|c|c|c|}
\hline $\begin{array}{l}10-97 \\
\text { (Foerder) }\end{array}$ & $\begin{array}{l}\text { Aviad Heifetz } \\
\text { Enrico Minelli }\end{array}$ & $\begin{array}{l}\text { Informational Smallness in Rational Expectations } \\
\text { Equilibria }\end{array}$ \\
\hline $\begin{array}{l}11-97 \\
\text { (Foerder) }\end{array}$ & $\begin{array}{l}\text { G.M.Milesi-Ferretti } \\
\text { Assaf Razin }\end{array}$ & $\begin{array}{l}\text { Current Account Deficits and Capital Flows in East } \\
\text { Asia and Latin America: Are the Nineties Different } \\
\text { from the Early Eighties? }\end{array}$ \\
\hline $\begin{array}{l}12-97 \\
\text { (Sackler) }\end{array}$ & $\begin{array}{l}\text { Assaf Razin } \\
\text { Efraim Sadka } \\
\text { Chi-Wa Yuen }\end{array}$ & $\begin{array}{l}\text { A Pecking Order of Capital Inflows and International } \\
\text { Tax Principles }\end{array}$ \\
\hline $\begin{array}{l}13-97 \\
\text { (Foerder) }\end{array}$ & $\begin{array}{l}\text { Assaf Razin } \\
\text { Chi-Wa Yuen }\end{array}$ & $\begin{array}{l}\text { Income Convergence Within an Economic Union: } \\
\text { The Role of Factor Mobility and Coordination }\end{array}$ \\
\hline $\begin{array}{l}14-97 \\
\text { (Foerder) }\end{array}$ & Omri Ben-Shahar & Should Products Liability be Based on Hindsight? \\
\hline $\begin{array}{l}15-97 \\
\text { (Sackler) }\end{array}$ & M June Flanders & Left- and Right-Endogenous Money: A Tale of Two Books \\
\hline $\begin{array}{l}16-97 \\
\text { (Foerder) }\end{array}$ & $\begin{array}{l}\text { Bent E.Sorensen } \\
\text { Oved Yosha }\end{array}$ & $\begin{array}{l}\text { Federal Insurance of U.S. States: An Empirical } \\
\text { Investigation }\end{array}$ \\
\hline $\begin{array}{l}17-97 \\
\text { (Foerder) }\end{array}$ & $\begin{array}{l}\text { Jacob Glazer } \\
\text { Ariel Rubinstein }\end{array}$ & $\begin{array}{l}\text { Debates and Decisions: On a Rationale of } \\
\text { Argumentation Rules }\end{array}$ \\
\hline $\begin{array}{l}18-97 \\
\text { (Sackler) }\end{array}$ & $\begin{array}{l}\text { Hedva Ber } \\
\text { Yishay Yafeh } \\
\text { Oved Yosha }\end{array}$ & $\begin{array}{l}\text { Conflict of Interest in Universal Banking: Evidence } \\
\text { from the Post-Issue Performance of IPO Firms }\end{array}$ \\
\hline $\begin{array}{l}19-97 \\
\text { (Foerder) }\end{array}$ & $\begin{array}{l}\text { Yoram Weiss } \\
\text { Chaim Fershtman }\end{array}$ & $\begin{array}{l}\text { Social Status and Economic Performance: } \\
\text { A Survey }\end{array}$ \\
\hline $\begin{array}{l}20-97 \\
\text { (Foerder) }\end{array}$ & $\begin{array}{l}\text { Assaf Razin } \\
\text { Efraim Sadka }\end{array}$ & Globalization: Public Economics Policy Perspectives \\
\hline $\begin{array}{l}21-97 \\
\text { (Sackler) }\end{array}$ & $\begin{array}{l}\text { Neil Gandal } \\
\text { Michael Kende } \\
\text { Rafael Rob }\end{array}$ & $\begin{array}{l}\text { The Dynamics of Technological Adoption in } \\
\text { Hardware/Software Systems: The Case of Compact } \\
\text { Disk Players }\end{array}$ \\
\hline $\begin{array}{l}22-97 \\
\text { (Foerder) }\end{array}$ & $\begin{array}{l}\text { Zvi Eckstein } \\
\text { Pedro Mira } \\
\text { Kenneth I.Wolpin }\end{array}$ & $\begin{array}{l}\text { A Quantitative Analysis of Swedish Fertility Dynamics: } \\
1751-1990\end{array}$ \\
\hline $\begin{array}{l}23-97 \\
\text { (Foerder) }\end{array}$ & $\begin{array}{l}\text { Francesca Cornell } \\
\text { Oved Yosha }\end{array}$ & Stage Financing and the Role of Convertible Debt \\
\hline $\begin{array}{l}24-97 \\
\text { (Sackler) }\end{array}$ & $\begin{array}{l}\text { Zvi Eckstein } \\
\text { Kenneth I.Wolpin }\end{array}$ & $\begin{array}{l}\text { Youth Employment and Academic Performance in } \\
\text { High School }\end{array}$ \\
\hline $\begin{array}{l}25-97 \\
\text { (Foerder) }\end{array}$ & $\begin{array}{l}\text { G.M.Milesi-Ferretti } \\
\text { Assaf Razin }\end{array}$ & $\begin{array}{l}\text { Origins of Sharp Reductions in Current Account } \\
\text { Deficits: An Empirical Analysis }\end{array}$ \\
\hline $\begin{array}{l}26-97 \\
\text { (Foerder) }\end{array}$ & Ariel Rubinstein & Definable Preferences: An Example \\
\hline $\begin{array}{l}27-97 \\
\text { (Sackler) }\end{array}$ & $\begin{array}{l}\text { Arthur Fishman } \\
\text { Rafael Rob }\end{array}$ & An Equilibrium Model of Firm Growth and Industry Dynamics \\
\hline $\begin{array}{l}28-97 \\
\text { (Foerder) }\end{array}$ & $\begin{array}{l}\text { Ariel Rubinstein } \\
\text { Lin Zhou }\end{array}$ & Choice Problems with a "Reference" Point \\
\hline
\end{tabular}




\begin{tabular}{|c|c|c|}
\hline $\begin{array}{l}29-97 \\
\text { (Foerder) }\end{array}$ & $\begin{array}{l}\text { Chaim Fershtman } \\
\text { Neil Gandal } \\
\text { Sarit Markovich }\end{array}$ & $\begin{array}{l}\text { Estimating the Effect of Tax Reform in Differentiated } \\
\text { Product Oligopolistic Markets }\end{array}$ \\
\hline $\begin{array}{l}30-97 \\
\text { (Sackler) }\end{array}$ & $\begin{array}{l}\text { Alex Cukierman } \\
\text { Mariano Tommasi }\end{array}$ & When Does it Take a Nixon to Go to China? \\
\hline $\begin{array}{l}31-97 \\
\text { (Foerder) }\end{array}$ & $\begin{array}{l}\text { Jean-Marie Viaene } \\
\text { Itzhak Zilcha }\end{array}$ & $\begin{array}{l}\text { Capital Markets Integration, Growth and Income } \\
\text { Distribution: A Dynamic Analysis }\end{array}$ \\
\hline $\begin{array}{l}32-97 \\
\text { (Foerder) }\end{array}$ & $\begin{array}{l}\text { Assaf Razin } \\
\text { Efraim Sadka } \\
\text { Chi-Wa Yuen }\end{array}$ & $\begin{array}{l}\text { Implications of the Home Bias: A Pecking Order of } \\
\text { Capital Inflows and Corrective Taxation }\end{array}$ \\
\hline $\begin{array}{l}33-97 \\
\text { (Sackler) }\end{array}$ & $\begin{array}{l}\text { Assaf Razin } \\
\text { Efraim Sadka } \\
\text { Chi-Wa Yuen }\end{array}$ & $\begin{array}{l}\text { Quantitative Implications of the Home Bias: Foreign Under- } \\
\text { investment, Domestic Oversaving and Corrective Taxation }\end{array}$ \\
\hline $\begin{array}{l}34-97 \\
\text { (Foerder) }\end{array}$ & $\begin{array}{l}\text { Oded Hochman } \\
\text { David Pines }\end{array}$ & $\begin{array}{l}\text { On the Agglomeration of Non-Residential Activities in } \\
\text { an Urban Area }\end{array}$ \\
\hline $\begin{array}{l}35-97 \\
\text { (Foerder) }\end{array}$ & Yael Artstein & Wage Rigidity in Israel: Institutions vs. Market Forces \\
\hline $\begin{array}{l}36-97 \\
\text { (Sackler) }\end{array}$ & $\begin{array}{l}\text { Assaf Razin } \\
\text { Efraim Sadka } \\
\text { Chi-Wa Yuen }\end{array}$ & $\begin{array}{l}\text { Channelling Domestic Savings into Productive Investment } \\
\text { under Asymmetric Information: The Essential Role of } \\
\text { Foreign Direct Investment }\end{array}$ \\
\hline $\begin{array}{l}37-97 \\
\text { (Foerder) }\end{array}$ & $\begin{array}{l}\text { Adriana Arreaza } \\
\text { Bent E.Sorensen } \\
\text { Oved Yosha }\end{array}$ & $\begin{array}{l}\text { Consumption Smoothing Through Fiscal Policy in } \\
\text { OECD and EU Countries }\end{array}$ \\
\hline $1-98$ & $\begin{array}{l}\text { Assaf Razin } \\
\text { Efraim Sadka } \\
\text { Chi-Wa Yuen }\end{array}$ & $\begin{array}{l}\text { Channelling Domestic Savings into Productive Investment } \\
\text { Under Asymmetric Information: The Essential Role of } \\
\text { Foreign Direct Investment (Revised version of \#36-97) }\end{array}$ \\
\hline $2-98$ & $\begin{array}{l}\text { Charlotte Ostergaard } \\
\text { Bent E.Sorensen } \\
\text { Oved Yosha }\end{array}$ & $\begin{array}{l}\text { Permanent Income, Consumption, and Aggregate Constraints: } \\
\text { Evidence from U.S. States }\end{array}$ \\
\hline $3-98$ & $\begin{array}{l}\text { Zvi Eckstein } \\
\text { Yoram Weiss }\end{array}$ & $\begin{array}{l}\text { The Absorption of Highly Skilled Immigrants: Israel, } \\
\text { 1990-1995 }\end{array}$ \\
\hline $4-98$ & $\begin{array}{l}\text { Audra J.Bowlus } \\
\text { Zvi Eckstein }\end{array}$ & $\begin{array}{l}\text { Discrimination and Skill Differences in an Equilibrium } \\
\text { Search Model }\end{array}$ \\
\hline $5-98$ & $\begin{array}{l}\text { Karnit Flug } \\
\text { Zvi Hercowitz }\end{array}$ & $\begin{array}{l}\text { Equipment Investment and the Relative Demand for } \\
\text { Skilled Labor: International Evidence }\end{array}$ \\
\hline $6-98$ & Chaim Fershtman & $\begin{array}{l}\text { A Note on Multi-lssue Two-Sided Bargaining: } \\
\text { Bilateral Procedures }\end{array}$ \\
\hline $7-98$ & $\begin{array}{l}\text { Elhanan Helpman } \\
\text { Antonio Rangel }\end{array}$ & $\begin{array}{l}\text { Adjusting to a New Technology: Experience } \\
\text { and Training }\end{array}$ \\
\hline $8-98$ & $\begin{array}{l}\text { Elhanan Helpman } \\
\text { Torsten Persson }\end{array}$ & Lobbying and Legislative Bargaining \\
\hline $9-98$ & $\begin{array}{l}\text { Gene M. Grossman } \\
\text { Elhanan Helpman }\end{array}$ & Competing for Endorsements \\
\hline
\end{tabular}

